\title{
Assessment of Urban Pluvial Flood Risk and Efficiency of Adaptation Options Through Simulations - A New Generation of Urban Planning Tools
}

Löwe, Roland; Urich, Christian; Sto. Domingo, Niña Donna Farpale; Mark, Ole; Deletic, Ana; ArnbjergNielsen, Karsten

Published in:

Journal of Hydrology

Link to article, DOI:

10.1016/j.jhydrol.2017.05.009

Publication date:

2017

Document Version

Peer reviewed version

Link back to DTU Orbit

Citation $(A P A)$ :

Löwe, R., Urich, C., Sto. Domingo, N. D. F., Mark, O., Deletic, A., \& Arnbjerg-Nielsen, K. (2017). Assessment of Urban Pluvial Flood Risk and Efficiency of Adaptation Options Through Simulations - A New Generation of Urban Planning Tools. Journal of Hydrology, 550, 355-367. https://doi.org/10.1016/j.jhydrol.2017.05.009

\section{General rights}

Copyright and moral rights for the publications made accessible in the public portal are retained by the authors and/or other copyright owners and it is a condition of accessing publications that users recognise and abide by the legal requirements associated with these rights.

- Users may download and print one copy of any publication from the public portal for the purpose of private study or research.

- You may not further distribute the material or use it for any profit-making activity or commercial gain

- You may freely distribute the URL identifying the publication in the public portal 


\section{Assessment of Urban Pluvial Flood Risk and \\ 2 Efficiency of Adaptation Options Through \\ 3 Simulations - A New Generation of Urban Planning \\ 4 Tools}

Roland Löwe ${ }^{\mathrm{a}, \mathrm{d}, *}$, Christian Urich ${ }^{\mathrm{b}, \mathrm{d}}$, Nina Sto. Domingo ${ }^{\mathrm{c}}$, Ole Mark ${ }^{\mathrm{c}}$, Ana Deletic ${ }^{\mathrm{b}}$, Karsten Arnbjerg-Nielsen ${ }^{\mathrm{a}, \mathrm{d}}$

${ }^{a}$ Department of Environmental Engineering, Technical University of Denmark (DTU Environment), Miljøvej B115, Kgs. Lyngby, 2800, Denmark, rolo@env.dtu.dk, karn@env.dtu.dk

${ }^{\mathrm{b}}$ Department of Civil Engineering, 23 College Walk, Monash University, Clayton, VIC, 3800, Australia, christian.urich@monash.edu, ana.deletic@monash.edu

'DHI Water and Environment, Agern Allé 5, Hørsholm, 2970, Denmark, nsd@dhigroup.com, omj@dhigroup.com

${ }^{\mathrm{d} C}$ Cooperative Research Centre (CRC) for Water Sensitive Cities, Clayton, VIC 3800, Australia

\section{ABSTRACT}

We present a new framework for flexible testing of flood risk adaptation strategies in a variety of urban development and climate scenarios. This framework couples the 1D-2D hydrodynamic simulation package MIKE Flood with the agent-based urban development model DAnCE4Water and provides the possibility to systematically test various flood risk adaptation measures ranging from large infrastructure changes over decentralised water management to urban planning policies. We have tested the framework in a case study in Melbourne, Australia considering 9 scenarios for urban development and climate and 32 potential combinations of flood adaptation measures. We found that the performance of adaptation measures strongly depended on the considered climate and urban development scenario and the other implementation measures implemented, suggesting that adaptive strategies are preferable over one-off investments. Urban planning policies proved to be an efficient means for the reduction of flood risk, while implementing property buyback and pipe increases in a guideline-oriented manner was too costly. Random variations in location and time point of urban development could have significant impact on flood risk and would in some cases outweigh the benefits of less efficient adaptation strategies. The results of our setup can serve as an input for robust decision making frameworks and thus support the identification of flood risk adaptation measures that are economically efficient and robust to variations of climate and urban layout.

\section{KEYWORDS}

38 Flood risk; urban development; climate change; agent-based modelling; 


\section{INTRODUCTION}

The implementation of flood adaptation measures often involves very long planning horizons of 30 and more years, because measures are either time-consuming to implement, or require large investments, or both. Commonly, adaptation measures would be selected based on predictions of flood risk over the planning horizon. However, this approach is problematic, because typically only little is known about the future. For example, studies in various locations have shown that flood risk is strongly affected by climate change and urban growth and anticipated to increase over the next century (Ehret et al., 2008; Hinkel et al., 2014; Muis et al., 2015; Muller, 2007; Semadeni-Davies et al., 2008; Zhou et al., 2012; Zhu et al., 2007). However, projections of sea levels and rainfall are subject to large uncertainties (Hall et al., 2014; Madsen et al., 2014; Sun et al., 2007; Sunyer et al., 2014). Similarly, spatial and temporal projections of urban development depend on uncertain projections of population growth and economic development (Cohen, 2004; Granger and Jeon, 2007) and future societal preferences are virtually unknown.

In such a context, flood adaptation options or, more generally, policies based on predictions of the future conditions can prove to be very fragile (Walker et al., 2001) and necessary investments may well be postponed for fear of making irreversible choices (Aerts et al., 2014). As proposed already by (Walker et al., 2001), new decision tools therefore point in the direction of testing adaptation options for a variety of potential future developments and assessing their robustness (Gersonius et al., 2012; Kwakkel et al., 2015; Prudhomme et al., 2010). Such scenario based evaluations have become quite common in the assessment of flood risks (Huong and Pathirana, 2013; Muis et al., 2015; Poelmans et al., 2011; Sekovski et al., 2015), but are difficult to apply for design purposes due to the simulation effort involved and are therefore usually performed only for few selected scenarios (Zhou et al., 2012) or apply very simplified models (Kwakkel et al., 2015; Zhu et al., 2007).

In this article, we demonstrate the development and application of a tool which allows for a systematic assessment of flood adaptation options in urban environments for a variety of potential futures. We have linked the urban development model DAnCE4Water (Urich and Rauch, 2014) with the 1D-2D hydrodynamic modelling engine MIKE FLOOD (DHI, 2013) to allow dynamic linkages between climate change impacts, city development, and adaptation options. DAnCE4Water applies an agent-based approach to simulate the evolution of the urban form at parcel level detail and thus directly provides information on the shape and location of urban features such as buildings or streets. This approach allows for a consideration of spatio-temporal interdependencies between flood hazard, exposure and vulnerability as suggested by (Merz et al., 2014) as these may lead to undesired surprises in flood risk management (Merz et al., 2015). Further, the effect of, e.g., zoning policies can directly be modelled in an easily understandable manner. The agent-based approach was therefore preferred over the raster based black box methods applied in most other hydrological studies considering urban development or land use change (Barreira González et al., 2015; Hoymann, 2010; Muis et al., 2015; Poelmans and Van Rompaey, 2010; Sekovski et al., 2015). In line with a general development in the field of urban modelling (Batty, 2009), the purpose of this setup is not to predict future developments, but to perform exploratory analysis and to support dialogue between stakeholders. 
Urban flood adaptation measures can take effect on runoff formation, transport and retention in the drainage network, as well as surface flow paths. A tool for assessing the effect of adaptation measures thus needs to be able to consider all of these effects. For this reason, we chose to apply a coupled 1D-2D hydrodynamic model for the assessment of flood hazards. Despite their complexity, such models have been shown to be applicable also for large urban catchments (Henonin et al., 2015; Russo et al., 2015) and in an automated manner (Meneses et al., 2015).

The aim of this paper is

1. to illustrate the new tool for systematic testing of flood risk adaptation options,

2. to demonstrate that it is possible to assess various adaptation options for a variety of future pathways using a detailed urban development and hydrodynamic modelling approach,

3. to highlight opportunities for further development of such a setup, and

4. to demonstrate the benefits of systematically screening adaptation options for a variety of potential futures.

\section{Material AND Methods}

\subsection{GENERAL SETUP}

Our aim was to provide a new tool that supports the systematic assessment of a variety of flood adaptation options under a variety of potential urban development and climate scenarios. Figure 1 illustrates the modelling setup we applied. In this setup, the urban development modelling platform DAnCE4Water (Urich and Rauch, 2014) was integrated with the hydrodynamic model MIKE FLOOD using ArcPy (ESRI, 2012) and the GDAL libraries (GDAL Development Team, 2014) through Python.

We tested so-called pathways defined by different combinations of:

- Scenarios, manifested in varying external drivers such as

0 different population growth rates and

o climate scenarios,

- Flood adaptation strategies such as

o infrastructural measures to be implemented or

0 land use management strategies.

The urban development model then performed a simulation along the pathway over a planning horizon from the year 2010 until 2060. Every 10 years, the current urban development state was transferred to the hydrodynamic model and the current flood risk was assessed using design rains derived according to the considered climate scenario.

Each pathway thus consisted of 6 flood risk assessments that varied depending on the number of households currently present in the catchment, the type and location of buildings, the current state of the climate and the flood adaptation options currently implemented. We refer to Section 2.3 for a detailed description of the urban development and climate scenarios we considered, as well as the implemented flood adaptation options. 
Note that the setup illustrated in Figure 1 allows for conditioning the urban development model on results from the hydrodynamic simulation. This opens up the possibility to optimize adaptation options along a pathway as suggested by (Kwakkel et al., 2015).

Further, while our work was focused on flood risk assessment and the development of adaptation options in a highly uncertain future, the work presented here can be embedded into a more general urban planning context. The urban development and the flood adaptation options implemented along a pathway impact other factors of the water household and urban liveability. Such factors can be assessed by linking other model blocks to the urban development model and including their results in a cost benefit assessment. Examples of such extensions are the consideration of effects on urban heat, the provision of ecosystem services or the efficiency of transport connections. In the terminology of (Merz et al., 2010), such a simulation setup aims to extend the problem domain (level 4) for flood risk management because adaptation options are designed to fulfil multiple purposes rather than the sole reduction of flood risk.

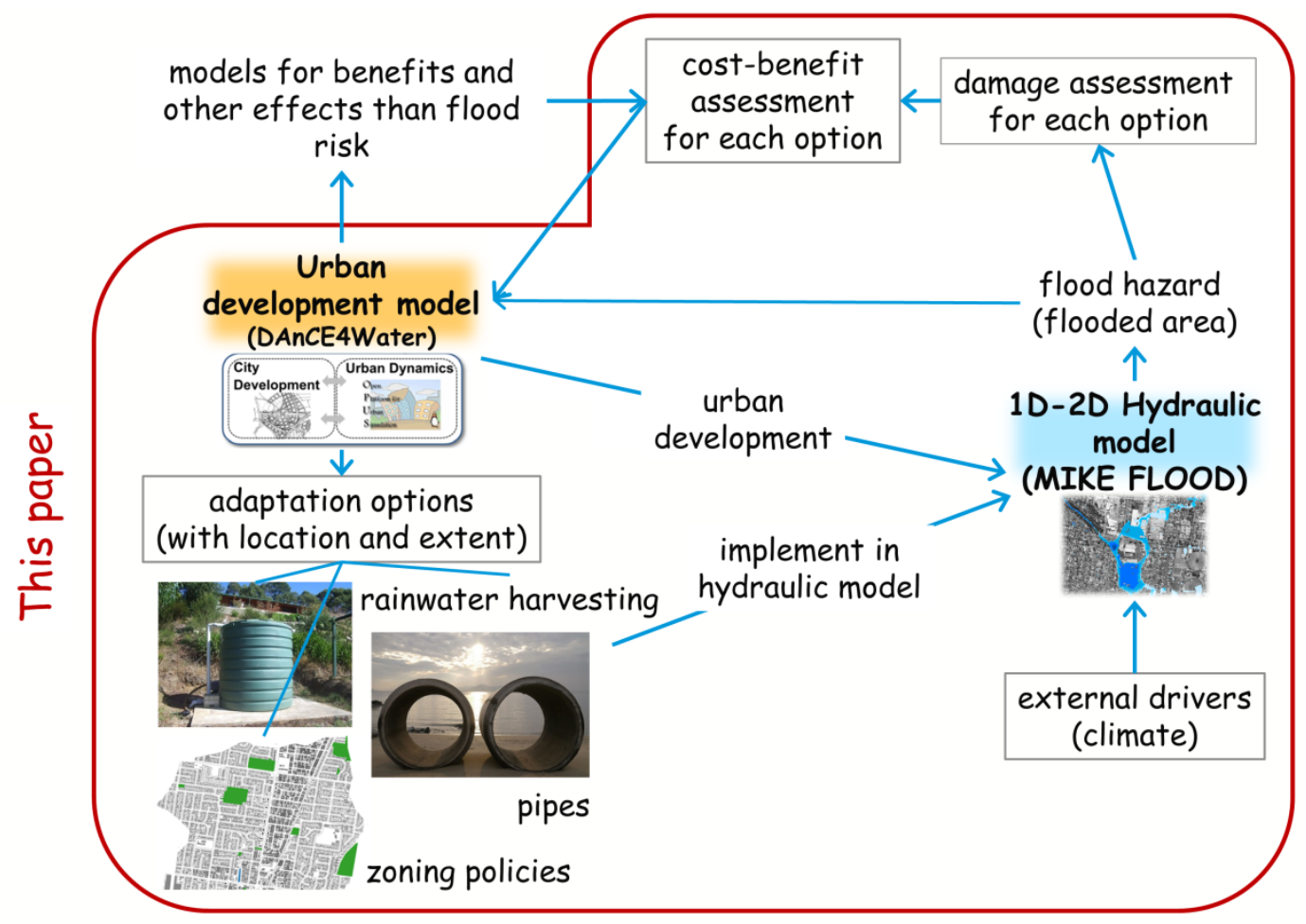

Figure 1. Schematic coupling between urban development model (DAnCE4Water) and 1D-2D hydrodynamic model (MIKE FLOOD).

\subsection{Case Study Catchment}

We have tested the flood risk assessment tool in an urban case study in Australia. The Scotchman's Creek catchment covers an area of 300 ha of mostly residential land use in the south-eastern suburbs of Melbourne, Australia. The catchment has undergone strong urban development over the last decades. It was applied in previous studies that investigated the implementation of water sensitive urban design (WSUD) infrastructures (Bach et al., 2015, 2013). 
Figure 2 provides an overview of the catchment together with the simulated flood areas for a design rain with return period 100 years. Flood risk in the catchment is dominated by pluvial flooding, mainly as a result of urbanization in low-lying areas of the catchment. A 1D-2D hydraulic model was set up for our case study. Details on the available dataset are provided in the supporting material. As input for the hydraulic simulations we applied design rainfalls that were extracted from Australian guidelines (Australia Institution of Engineers, 1987; French and Jones, 2012).

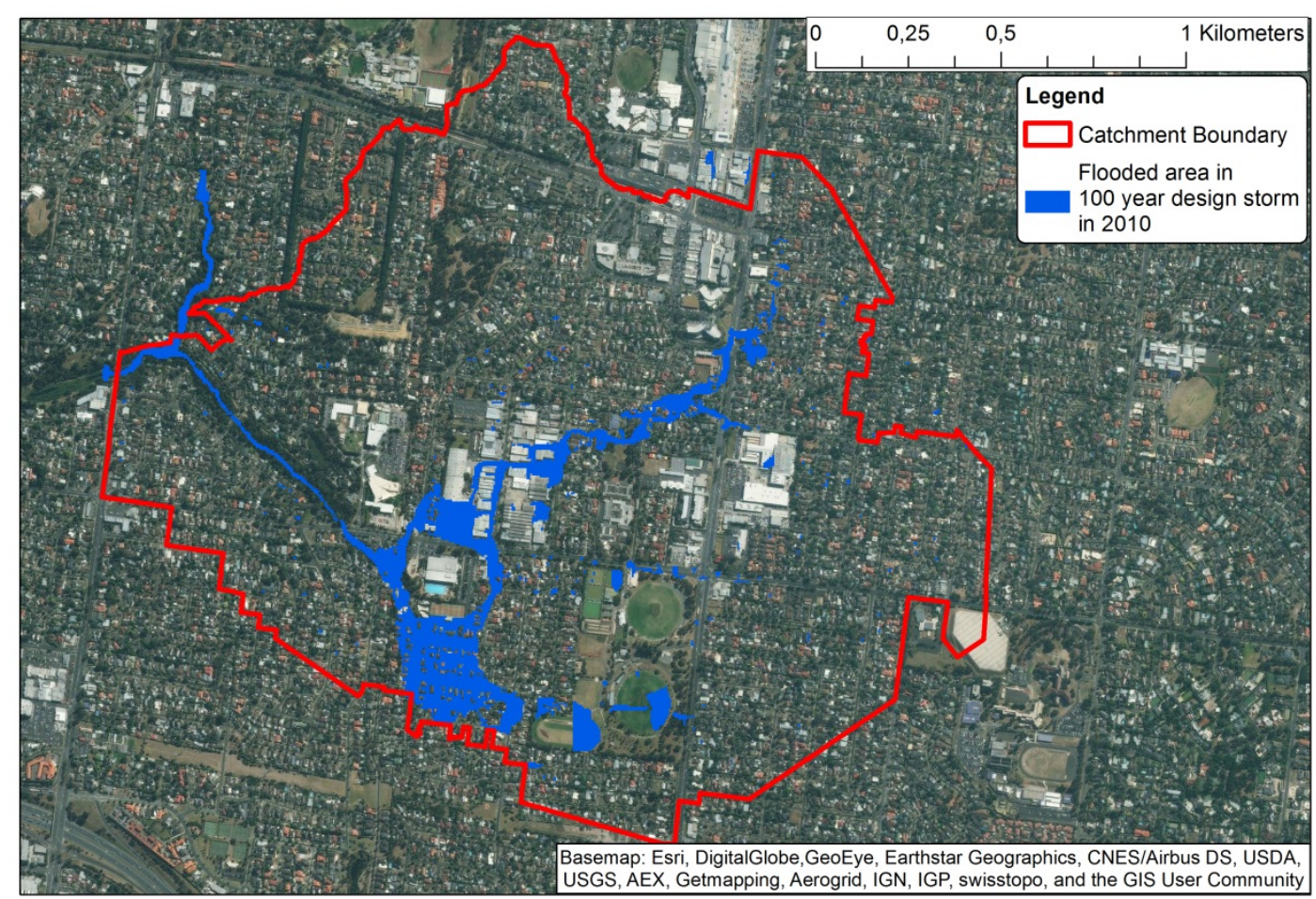

Figure 2. Scotchman's Creek catchment in Melbourne, Australia with flooded area for 100yr return period.

\subsection{Pathways}

To test the performance of flood risk adaptation strategies for a variety of potential futures, we need to define realistic ranges for future climate and urban development as well as adaptation strategies to consider. We therefore defined 3 potential population growth and 3 climate scenarios, resulting in 9 different scenarios for future development. These were subsequently used to test a total of 32 potential combinations of adaptation strategies. Each candidate strategy was tested for each of the 9 future scenarios, leading to 288 potential pathways.

\subsubsection{Future Scenarios}

We have considered a planning horizon of 50 years starting in 2010 and ending in 2060. Changes of flood risk in the catchment are subject mainly to two unknowns. Firstly, it is unclear how many people will live in the catchment in the future, where they will settle and to what extent their properties and infrastructure will be vulnerable to flooding. As the location and type of urban development can at least in 
principle be directed by policies, we have considered these factors as adaptation options described in Section 2.3.2. The degree of population growth, on the other hand, is strongly influenced by external factors such as economic development or immigration. As an example for the application of our framework, we derived ranges of potential population developments for the catchment informed by the population projections for greater Melbourne downscaled to the Monash Local Government Area (The State of Victoria - Department of Transport Planning and Local Infrastructure, 2014). We defined three population growth scenarios in which the number of households in the catchment increased by rates of $0.4,0.8$ and $1.2 \%$ per year.

Secondly, the characteristics of future rainfall are unknown. (CSIRO and Bureau of Meteorology, 2015) project a change of maximum daily rain intensities by 2080 in South Australia between -5 and 5\% considering only natural variability and between $2 \%$ and 22\% under emission scenario RCP8.5. Changes in extreme rain intensities for short durations can be subject to even larger variation as demonstrated by (Arnbjerg-Nielsen, 2012). We have therefore considered three climate scenarios covering a large range of potential climates with annual increases in design rain intensity of $0,0.5$ and $1 \%$.

Both, population growth and climate change are expected to occur continuously over the planning horizon. We assumed a linear increase of design rain intensities over the planning horizon and exponential population growth as illustrated in Figure 3.
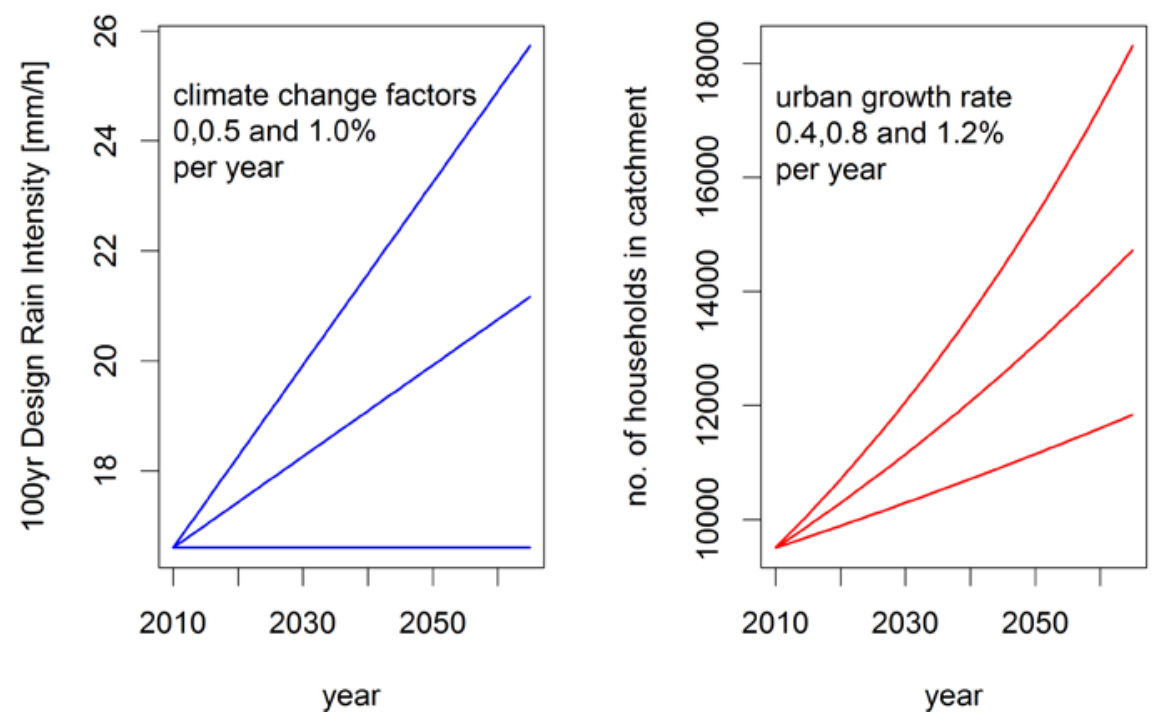

Figure 3. Examples for the evolvement of drivers for flood risk over a planning horizon. Left - design rain intensity as a result of climate change, right - no. of households in the catchment as a result of population growth.

\subsubsection{Adaptation Strategies}

We have considered a number of structural and non-structural measures that aim at reducing flood risk in the catchment. To illustrate the potential of the coupled software framework, we considered a spectrum of options ranging from the implementation of urban planning policies to classical engineering solutions. 
The considered options were:

\section{Master plans controlling the form of urban development.}

In the business as usual scenario (BAU) urban development continued as observed in the past with uncontrolled urban sprawl where population growth is largely accommodated by the development of new detached single-unit houses. Opposed to the BAU scenario, the water sensitive city (WSC) scenario favours a more compact urban form and implements multi-storey buildings and apartment blocks along transport corridors as illustrated in Figure 4 for a scenario simulated until the year 2060 .

\section{Flood zoning.}

This strategy focused on reducing the exposure to flood hazards through a buyback of properties. During any year of the planning horizon, buildings which were at risk of flooding more often than once in 100 years in the status situation in 2010 would be assigned a chance of $3 \%$ to be bought back in the year under consideration.

3. Large scale implementation of rainwater harvesting facilities (RWHT). We considered four scenarios, where rainwater tanks were implemented randomly throughout the catchment in the urban development model. For each year during the planning horizon any building without rainwater harvesting would have a chance of either $0,1,3$ or $5 \%$ to have a rainwater tank implemented. The volume of each RWHT unit was assumed to be approximately $2 \mathrm{~m}^{3}$.

\section{Increase in pipe capacity.}

In this strategy the dimension of the stormwater pipes was increased until flooding no longer occurred more than once in 10 years anywhere in the catchment in the status situation in 2010.

The adaptation options represent four typical measures implemented in flood risk management, i.e. master planning control of future development, gradual implementation of measures throughout the catchment, development zoning allowing dynamic feedback mechanisms from increasing hazards into city development, and a one-off investment in increasing infrastructure. Adaptation options 1 to 3 were implemented as rules in the urban development model (see supporting material), while adaptation 4 was implemented by considering a modified hydraulic model in the simulations.

For cost-benefit assessment, we considered the positive effect of reduced drinking water demand in option 3, while no benefits apart from the reduction of flood risk were considered for the other options. Details on the model implementation, as well as the derivation of investment cost and benefits of the different adaptation measures are provided in the supporting material. 

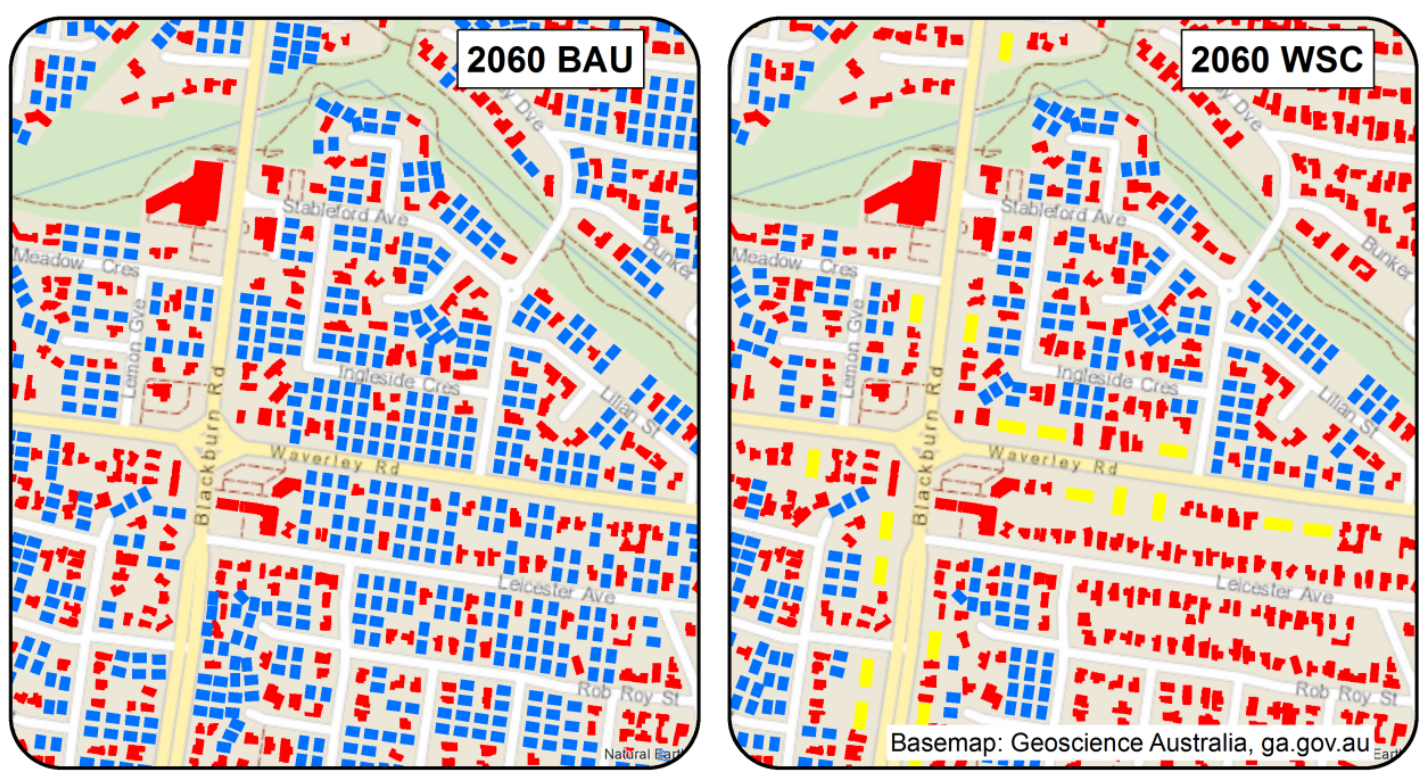

Legend
$\begin{array}{lll}\text { Existing buildings } & \text { Detached buildings } & \text { Apartment blocks } \\ \text { pre } 2010 & \text { simulated post } 2010 & \text { simulated post } 2010\end{array}$

Figure 4. Simulated urban form for the year 2060 for business as usual (BAU) and water sensitive cities (WSC) master plans assuming a growth rate of $1.2 \%$ / year

\subsubsection{Simulation of Pathways}

A total of 288 pathways were considered, resulting from 32 potential combinations of adaptation options and 9 scenarios. Urban development was simulated separately for each pathway except for those pathways involving an increase in pipe capacity, because this adaptation option was implemented independently from the urban development model. Flood risk was assessed every 10 years along each pathway for seven design storms with return periods ranging from 1 to 100 years, i.e., a total of 12,096 hydrodynamic simulations were performed.

\subsection{URBAN DEVELOPMENT}

Driven by external drivers such as population growth and climate change,

DAnCE4Water's urban and infrastructure development component evolves the urban environment at parcel level detail under different adaptation options (Urich and Rauch, 2014). Similar to UrbanSim (Waddell, 2002), the model uses an agent-based approach that simulates key actors and their interactions within the urban environment. Such approaches can, in principle, resemble closely the way stakeholders think and incorporate decision making at multiple levels (Matthews et al., 2007) and are thus useful to facilitate dialog between different stakeholders.

In our case, DAnCE4Water simulates city councils that introduce zoning regulations and upgrade the drainage system in response to increased flood risk, residential developers that build new buildings according to the zoning regulations, location preferences and pre-defined development patterns, and newly added (based on the 
population projections) or relocated households that according to their preferences choose to occupy a newly developed building and install rainwater harvesting tanks.

The urban development model was set up to replicate typical urban development patterns within the catchment. For the relevant simulation period between 2010 2060 two main development processes have been identified based on an analysis of aerial photos and census data from the Australian Bureau of Statistics for 1996, 2006, 2011 (Wong, 2014):

- the redevelopment of single family houses with 2-3 town houses depending on the parcel size (parcel splitting), and

- the combination of adjacent parcels to develop multi-storey apartment buildings.

Due to the small size of the catchment, no significant preference for the redevelopment of existing properties was identified, i.e., after defining population growth rate and zoning regulations, the model randomly selected parcels where to develop new buildings and randomly assigned households to the newly developed buildings. This implies that two urban development scenarios with equal growth rate and zoning regulations would not yield the exact same results, because buildings could be developed at different locations and / or different time points along the pathway.

Our approach for modelling urban development assumes that development is only manifested through the two processes named above and that development patterns do not change along the planning horizon. Further, we did not consider interactions between, for example, developments of the urban form and economy. While this level of simplification is a short-coming of our approach that needs to be addressed to gain a better understanding of the uncertainties related to the planning of urban water systems, this also implies that only few input data are required, which is different from most micro-simulation agent-based models used to predict urban development (Batty, 2009). However, the level of detailed required to simulate urban development patterns is still discussed in the literature (Crooks et al., 2008; Mikovits et al., 2015a). For a detailed description of the implemented urban development model and the underlying assumptions we refer to the supporting material.

\subsection{Flood Risk ASSESSMENT}

Flood risk was calculated by integrating the potential damages from flooding over the catchment area. Below, we discuss the quantification of these parameters.

\subsubsection{Simulation of Flood Hazards - Implementation of Urban Development and Flood Adaptation in the Hydrodynamic Model}

Flood hazards were assessed using the 1D-2D hydrodynamic modelling package MIKEFLOOD (DHI, 2013). Urban development and flood adaptation options could affect the simulated flood hazards in multiple ways:

- by changing the portion of rainfall that is converted to (fast) runoff,

- by modifying the stormwater pipe network, or

- by modifying the surface flow paths. 
We have implemented changes of the hydrodynamic model due to urban development and the implementation of flood adaptation strategies as shown in Table 1.

Buildings and streets were considered in the computation of impervious area percentages for the subcatchments of the hydrodynamic model and as features in the terrain model. Elevations in the terrain model were increased by $10 \mathrm{~m}$ in pixels containing buildings and reduced by $0.1 \mathrm{~m}$ in pixels containing streets. Urban development and flood zoning changed the number and location of buildings simulated by DAnCE4Water and in this way affected the hydrodynamic simulation. A conversion of building types to, e.g., multi-storey buildings was not explicitly considered in the hydrodynamic simulation, but would lead to a lower building density in the catchment and thus affect the impervious area and the number of buildings exposed to flood risk. Changes of the street layout were not simulated in the urban development model in this work, but would otherwise be implemented similarly to modifications of the building layer.

The implementation of rainwater harvesting facilities on a property was in this work considered by considering the roof area of a building with rainwater tank as pervious area during runoff computation. Modifications of the pipe network were implemented manually in a separate hydraulic model. Subsequently, this modified "template" pipe network was used to replace the existing pipe network in simulations involving the adaptation strategy "increase in pipe capacity“.

Table 1. States of the urban development model which are modified as a result of urban development and the implementation of planning policies and their implementation in the 1D-2D hydraulic model.

\begin{tabular}{|l|l|l|l|l|}
\hline $\begin{array}{l}\text { Modificatio } \\
\mathrm{n}\end{array}$ & $\begin{array}{l}\text { Output Urban } \\
\text { Development } \\
\text { Model }\end{array}$ & Runoff model & $\begin{array}{l}\text { Pipe } \\
\text { network }\end{array}$ & $\begin{array}{l}\text { Terrain } \\
\text { model }\end{array}$ \\
\hline $\begin{array}{l}\text { Addition / } \\
\text { removal of } \\
\text { buildings }\end{array}$ & $\begin{array}{l}\text { Polygon layer } \\
\text { containing } \\
\text { building } \\
\text { footprints }\end{array}$ & $\begin{array}{l}\text { Recomputation } \\
\text { of impervious } \\
\text { area according } \\
\text { to building } \\
\text { footprint }\end{array}$ & - & $\begin{array}{l}\text { Increase } \\
\text { elevation of } \\
\text { cells } \\
\text { containing } \\
\text { buildings by } \\
+10 \mathrm{~m}\end{array}$ \\
\hline $\begin{array}{l}\text { Change of } \\
\text { building } \\
\text { type ( } \\
\text { apartment } \\
\text { blocks) }\end{array}$ & $\begin{array}{l}\text { Different } \\
\text { building } \\
\text { footprint, also } \\
\text { leads to fewer } \\
\text { buildings in } \\
\text { urban } \\
\text { development } \\
\text { simulation }\end{array}$ & $\begin{array}{l}\text { Recomputation } \\
\text { of impervious } \\
\text { area according } \\
\text { to building } \\
\text { footprint }\end{array}$ & - & $\begin{array}{l}\text { Increase } \\
\text { elevation of } \\
\text { cells } \\
\text { containing } \\
\text { buildings by } \\
+10 m\end{array}$ \\
\hline $\begin{array}{l}\text { Modificatio } \\
\text { ns of street } \\
\text { layout }\end{array}$ & $\begin{array}{l}\text { Street layout } \\
\text { currently not } \\
\text { modified by } \\
\text { urban } \\
\text { development }\end{array}$ & - & & \\
\hline
\end{tabular}




\begin{tabular}{|l|l|l|l|l|}
\hline & model & & \\
\hline $\begin{array}{l}\text { Implementat } \\
\text { ion of rain } \\
\text { water } \\
\text { harvesting } \\
\text { tanks }\end{array}$ & $\begin{array}{l}\text { Flag rainwater } \\
\text { harvesting yes / } \\
\text { no in building } \\
\text { attributes }\end{array}$ & $\begin{array}{l}\text { Consider } \\
\text { building area as } \\
\text { pervious area }\end{array}$ & - & - \\
\hline $\begin{array}{l}\text { Modificatio } \\
\text { n of pipe } \\
\text { diameters }\end{array}$ & & - & $\begin{array}{l}\text { Transfer } \\
\text { predesigned } \\
\text { pipe layout } \\
\text { to hydraulic } \\
\text { model }\end{array}$ & - \\
\hline
\end{tabular}

\section{8}

\subsubsection{Evaluation of Flood Risk}

The 1D-2D hydrodynamic simulations resulted in raster layers of water depths simulated in the different pixels for different time points during a rain event. For illustrative purposes, we evaluated direct tangible flood damages in a unit cost approach (Handmer et al., 2003) by overlaying simulated flood areas, building and road layers. We refer to the supporting material for details.

For design of flood adaptation an estimator for expected annual flood damages $\left(E A D_{t}\right)$ occurring in any year $t$ is commonly derived as the integral over the damages $D_{t}\left(p_{t}\right)$ occurring for events with annual exceedance probability $p_{t}$ (Stedinger, 1997). As illustrated in Figure 5, flood risk changes over time as a result of changing hazards, exposure and vulnerabilities. Expected risk over the planning horizon then needs to be derived as the integral of expected annual damages over time (USACE, 1992). Assuming that expected damages are evaluated on an annual basis and considering a planning horizon of 50 years between 2010 and 2060, we obtain:

$E D=\sum_{t=2010}^{2060} \int_{0}^{1} D_{t}\left(p_{t}\right) d p_{t}$.

Eq. 1

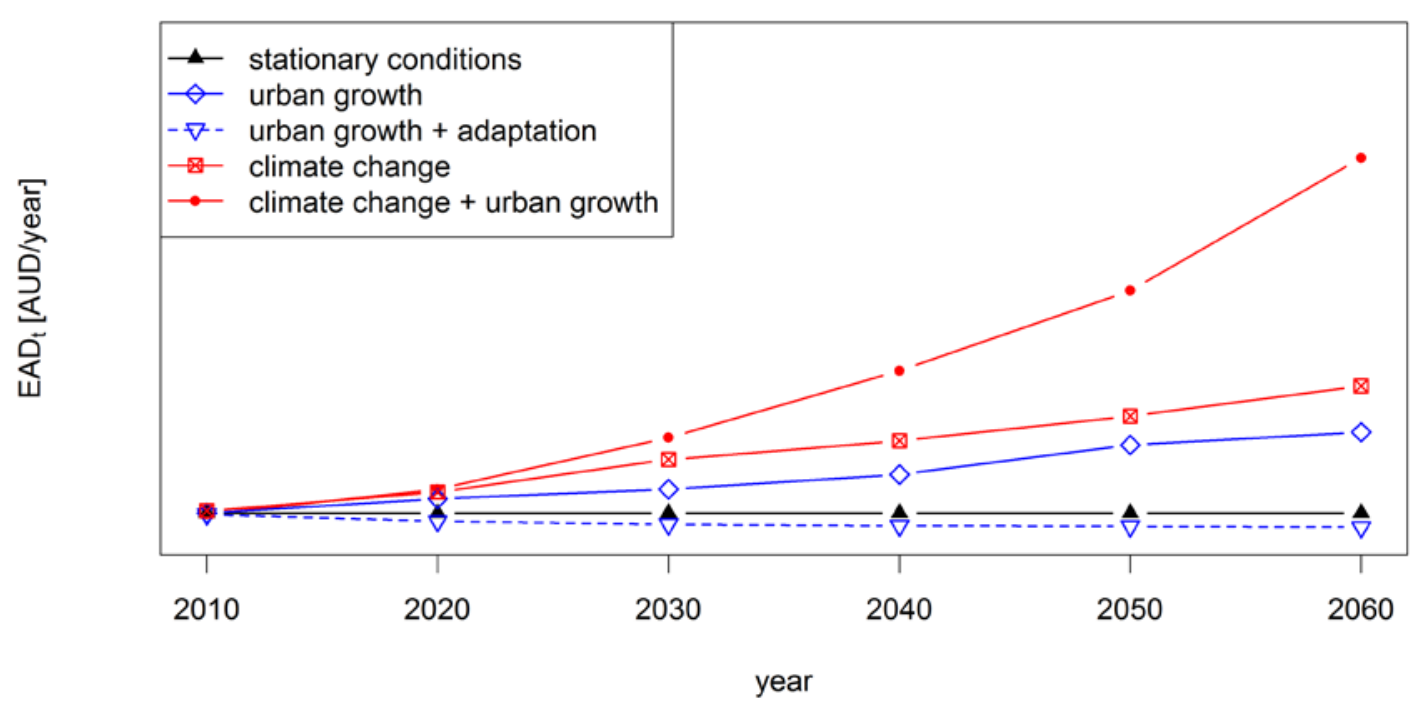

Figure 5. Schematic example for the change of expected annual damage (EAD) over a planning horizon for non-stationary conditions 
We assessed Eq. 1 numerically for each considered scenario by computing expected annual damages $\left(E A D_{t}\right)$ in 10 year intervals along the planning horizon and assuming a linear change of $E A D_{t}$ in between the sampling points. The rainfall was modified according to the considered climate scenario and the hydraulic model was updated based on the urban development simulated until the considered time point. $E A D_{t}$ were computed using the midpoint rule as described in (Olsen et al., 2015; USACE, 1989), based on simulated flood damages for 7 design rain storms with annual occurrence probabilities from 0.01 to 1 . Flood damages for annual occurrence probabilities smaller than 0.01 were assumed to correspond to the damages simulated for an event occurring with $p=0.01$.

In order to compare future reductions in flood risk to current cost of investment of an adaptation project, discounting of expected annual damages is commonly used in cost benefit analysis. This leads to the expected, discounted damage over the planning horizon $E D^{*}$ as shown in Eq. 2:

$E D^{*}=\sum_{t=2010}^{2060} E A D_{t} \frac{1}{(1+r)^{t-2010}}$

We applied a discounting rate of $r=0.014$ in our work as suggested by (Stern, 2007), but we note that the choice of discount rate is subject to scientific and ethical discussion (Mendelsohn, 2006; Olsen et al., 1998; Stern, 2016) and needs to be made in a local political context.

\subsection{Cost-Benefit Assessment}

In a planning context, investments into flood adaptation need to be compared against benefits obtained through the implementation of an adaptation strategy. We have therefore implemented a cost-benefit assessment to illustrate the applicability of our setup. We emphasize that this assessment was rudimentary, as the main focus of our work is on the illustration of the simulation setup.

To assess the efficiency of a flood adaptation strategy (or combination of strategies) $s$, we have computed the net present value $N P V_{s}$ for a specific urban development and climate scenario by comparing the reduction in flood damage against the investment cost $I_{s, t}$ and additional benefits $B_{s, t}$ occurring over the planning horizon. The approach is illustrated in Eq. 3 using the same discount rate as in Eq. 2. The reduction in flood damage was computed by comparing flood risk $E D_{r e f}^{*}$ without flood risk adaptation against the reduced flood risk $E D_{s}^{*}$ when the strategy was implemented. Computations were performed based on 2011 prices and it was assumed that no inflation would occur over the planning horizon.

$N P V_{s}=E D_{\text {ref }}^{*}-E D_{s}^{*}+\sum_{t=2010}^{t=2060}\left(B_{s, t}-I_{s, t}\right) \frac{1}{(1+r)^{t-2010}}$

For non-stationary climate and urban development conditions, the reduction in risk obtained for a specific flood adaptation measure needs to be computed against a baseline accounting for specific climate and urban development conditions (Stern, 2007; Zhou et al., 2012). Similarly, in our work $N P V_{s}$ was assessed separately for each scenario defined by a specific urban development rate and climate change 
factor. $E D_{s}^{*}, B_{s, t}$ and $I_{s, t}$ were computed for the specific scenario assuming that the adaptation measure was implemented, while $E D_{r e f}^{*}$ was the flood damage for the specific scenario without implementation of any flood adaptation.

\section{Results}

\subsection{EXPECTED ANNUAL Damage for Different AdAPTATION STRATEgIES}

Figure 6 illustrates how the simulated expected annual damage $E A D_{t}$ changed over the planning horizon as a result of changing design rain intensities and urban growth. We illustrated results for the business as usual scenario (BAU) without implementation of any adaptation strategies and for a separate implementation of each of the 4 considered adaptation strategies: implementation of rainwater harvesting tanks (RWHT), implementation of water sensitive city master plans supporting the development of apartment blocks (WSC), flood zoning and increase of the pipe networks capacity.

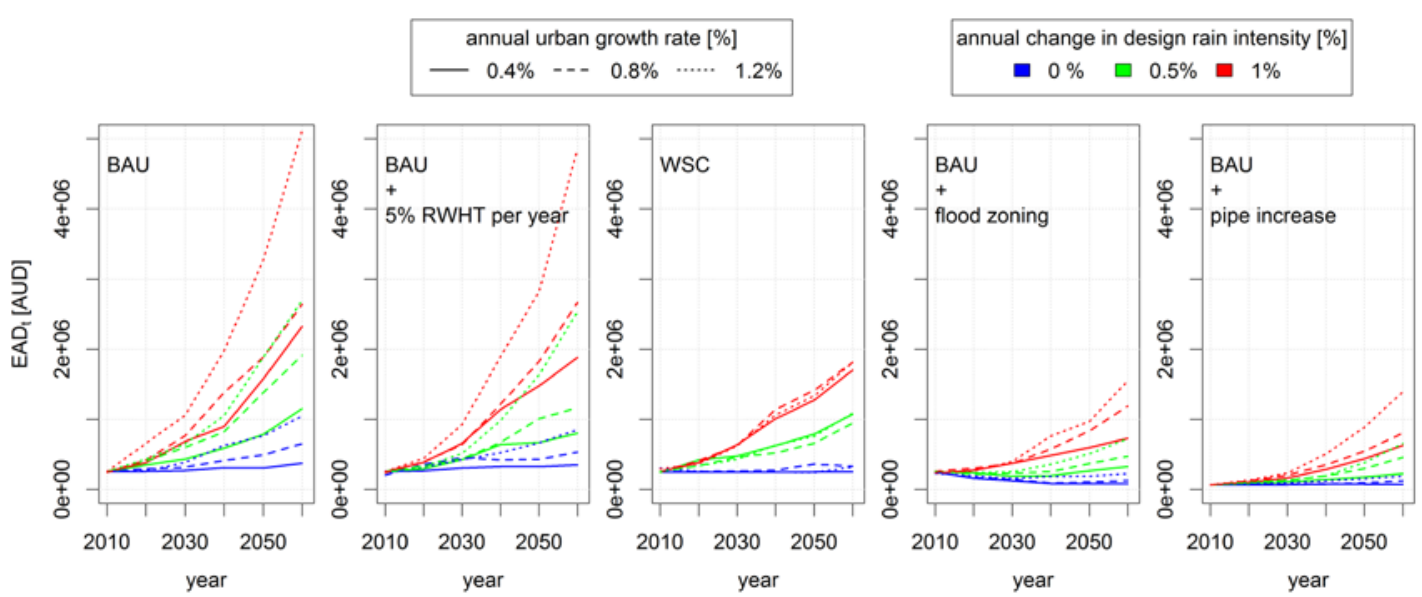

Figure 6. $E A D_{t}$ (Eq. 1) for the 9 considered scenarios and different combinations of adaptation options.

In all cases, flood risk was most affected by climate change. However, population growth could very much amplify the increase in flood risk and for the BAU scenario $E A D_{t}$ in $t=2060$ could be up to 2 times higher for a population growth rate of $1.2 \%$ than for a population growth rate of $0.8 \%$. A similar effect could be observed when adaptation options were implemented in the models. The only exception was the implementation of a WSC master plan, where population growth was largely balanced by the development of apartment blocks. The smaller number of buildings developed in this case would lead to a reduced flood risk as a result of reduced exposure.

The implementation of rainwater harvesting tanks had only minimal influence on the simulated flood risk, while the implementation of a water sensitive cities master plan (WSC), the implementation of flood zoning measures and the increase of pipe capacity all seemed similarly efficient in reducing flood risk. When implementing flood zoning measures, $E A D_{t}$ values would approach 0 in the scenario with lowest population growth rate and without climate change, as buildings were gradually removed from flood risk areas. Particularly for the scenarios with strong population 
growth, flood risk would increase over the planning horizon despite the implementation of flood zoning measures. The zoning policy did not account for potential future increases in flood area, so developments occurred in areas that would later become subject to flood risk.

Figure 7 depicts the expected damage $E D^{*}$ over the planning horizon (Eq. 2) computed for all pathways where an adaptation measure was implemented. For example, Figure 7 left compares the $E D^{*}$ values for all pathways where urban development followed a business as usual pattern (BAU) against those where a water sensitive cities (WSC) master plan was implemented. Similar trends as in Figure 6 can be observed. However, it becomes more clear that an increase of pipe capacity would in our case lead to the most efficient reduction in flood risk, with the lowest mean and the smallest spread of $E D^{*}$ over the different possible pathways. Similarly, flood zoning could efficiently reduce flood risk, while the implementation of a WSC master plan in various scenarios would lead to larger expected damages than for the aforementioned measures.

The implementation of rainwater harvesting measures appeared to have little effect on the expected damage values. In fact, median damages were slightly larger for the pathways involving a RWHT implementation rate of $1 \%$ than for those without RWHT, and for pathways involving a RWHT implementation rate of 5\% than for those with a rate of $3 \%$. The reduction of flood risk due to the reduced amount of urban runoff was in multiple cases outweighed by random variations in the simulated urban development and / or the implementation of zoning measures. For example, if properties in flood prone areas were relocated at the beginning of the planning horizon in one scenario, but not in another, this would have a larger effect on flood risk than the reduction in runoff resulting from rainwater harvesting measures. flood and implementation rates of RWHT of 3 and 5\%. Flood zoning was implemented as a gradual resettling of properties flooded in a 100 year event by random selection. In the pathway considering a RWHT implementation rate of 5\%, fewer buildings were removed from the flood prone area by 2040 than in the pathway considering a rate of $3 \%$. This lead to a larger expected damage $E D^{*}$ despite the implementation of RWHT. 

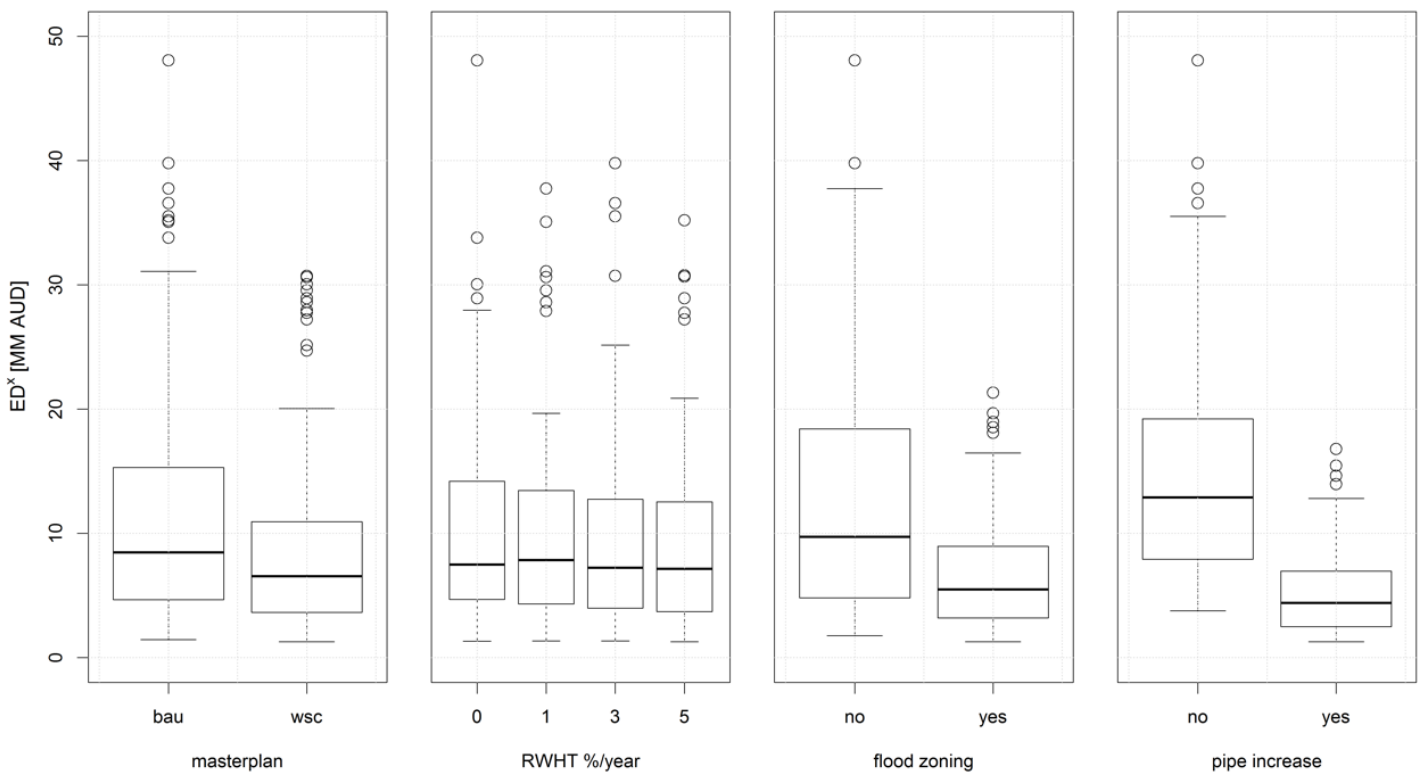

Figure 7. Boxplot of expected damage $E D^{*}$ over the planning horizon (Eq. 2) derived from simulation results over all scenarios and combination of adaptation measures where the considered measure was or was not implemented.

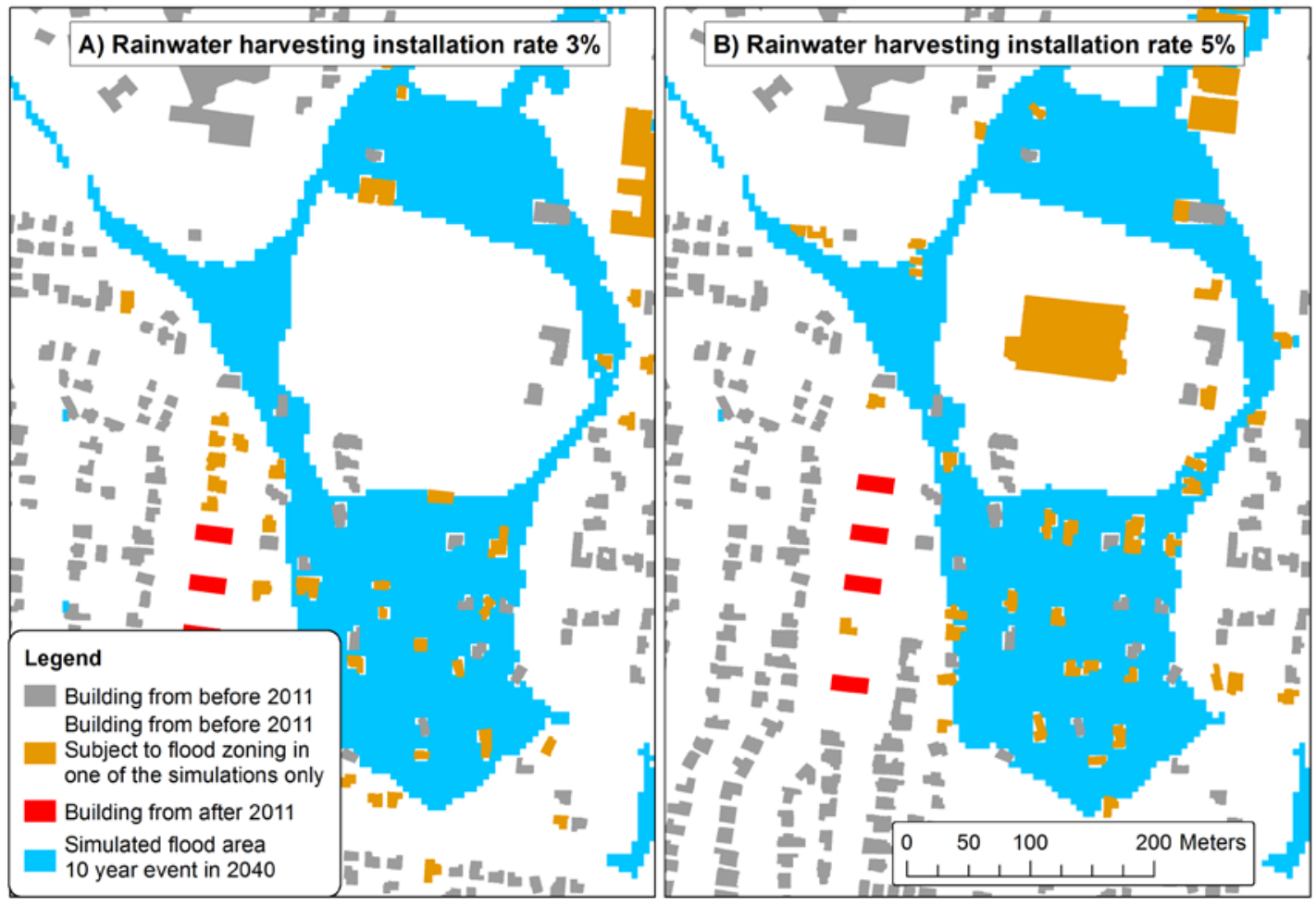

Figure 8. Building footprints and flood area for a 10 year event in the year 2040 for two scenarios considering a population growth rate of $1.2 \%$ and an annual increase in rain intensity of $1.0 \%$. Urban development was followed the WSC master plan and flood zoning was applied to new and existing properties. Rain water harvesting facilities were installed at rates of 3\% (left) and 5\% (right). Buildings developed before 2011 were marked grey if they still existed in 2040 in both simulations and orange otherwise. Buildings newly developed in the simulation after 2011 were marked red. 
Table 2 details the insights obtained from the analysis of Figure 7. The median and the standard deviation of the expected damage values $E D^{*}$ were derived from the simulation results for the different scenarios of population growth and climate change and depicted for all the combinations of adaptation measures. Analysing the results for the combination BAU master plan, no flood zoning and no increase in pipe capacity, as well as for the combination WSC master plan, no flood zoning and no increase in pipe capacity, it became clear that the implementation of RWHT did actually lead to a significant reduction in many pathways, particularly if not combined with other adaptation measures.

An increase in pipe capacity would lead to somewhat greater reductions in flood risk than the implementation of flood zoning measures, because the latter would take effect only gradually over the planning horizon. Similarly, the implementation of a WSC master plan would lead to somewhat smaller reductions in flood risk, because this measure would take effect only gradually over the planning horizon and reductions of flood risk would occur only somewhat randomly in space as a sideeffect of a more compact urban development.

Table 2. Mean and standard deviation of expected annual damage $E D^{*}$ (Eq. 2) derived for the 9 different climate and population growth scenarios for the different adaptation options considered.

\begin{tabular}{|c|c|c|c|c|c|c|c|c|c|c|c|c|c|c|c|c|}
\hline Master- & \multicolumn{16}{|c|}{ BAU } \\
\hline Flood- & \multicolumn{8}{|c|}{ NO } & \multicolumn{8}{|c|}{ YES } \\
\hline Pipe & \multicolumn{4}{|c|}{ NO } & \multicolumn{4}{|c|}{ YES } & \multicolumn{4}{|c|}{ NO } & \multicolumn{4}{|c|}{ YES } \\
\hline $\begin{array}{l}\mathrm{RWHT} \\
\text { rate } \\
\text { [\%/year] }\end{array}$ & 0 & 1 & 3 & 5 & 0 & 1 & 3 & 5 & 0 & 1 & 3 & 5 & 0 & 1 & 3 & 5 \\
\hline $\begin{array}{l}\text { Mean ED* } \\
{\left[10^{6} \text { AUD] }\right.}\end{array}$ & 30.2 & 28.2 & 27.2 & 25. & 7.5 & 6.9 & 6.8 & 6.1 & 11.5 & 11.2 & 10.0 & 9.7 & 5.1 & 4.9 & 4.4 & 4.4 \\
\hline $\begin{array}{l}\text { Stdv } \\
\text { ED* } \\
{\left[10^{6} \text { AUD] }\right.}\end{array}$ & 15.7 & 15.5 & 14. & 13. & 4.8 & 4.2 & 4.2 & 3.7 & 5.8 & 5.1 & 5.1 & 4.6 & 3.0 & 2.9 & 2.9 & 2.7 \\
\hline $\begin{array}{l}\text { Master- } \\
\text { plan }\end{array}$ & \multicolumn{16}{|c|}{ WSC } \\
\hline $\begin{array}{l}\text { Mean ED* } \\
{\left[10^{6} \text { AUD] }\right.}\end{array}$ & 19.1 & 18.2 & 17. & 17. & 5. & 5.2 & 5.0 & 4.8 & 8.9 & 8.7 & 7.7 & 8.0 & 3.5 & 3.5 & 3.1 & 3.1 \\
\hline $\begin{array}{l}\text { Stdv ED* } \\
{\left[10^{6} \text { AUD] }\right.}\end{array}$ & 8.5 & 9.0 & 7.6 & 8.2 & 3.0 & 3.0 & 2.8 & 2.8 & 4.3 & 3.6 & 3.1 & 3.9 & 2.2 & 1.9 & 1.6 & 1.7 \\
\hline
\end{tabular}

\subsection{Net Present Value for Different Adaptation Strategies}

Table 3 shows mean, minimum and maximum of $N P V_{S}$ derived from the simulation results for the different scenarios of population growth and climate change and depicted for all the combinations of adaptation measures. Considering the investment cost detailed in the supporting material, the implementation of a WSC master plan was the most efficient measure for reducing flood risk, because the investment cost for this measure was considered zero. 
For the other measures, the $N P V_{S}$ values were strongly affected by high investment cost. The implementation of RWHT would have a positive $N P V_{S}$ in a number of pathways if not combined with any other flood adaptation measures. In this case, rainwater harvesting could exploit its full potential for reducing flood risk. When combined with other flood adaptation measures, the contribution of rainwater harvesting to flood risk reduction was much smaller, while the investment cost were still fully applicable.

Increasing the capacity of the pipe system to be able to handle a 10 year storm required investments that strongly exceeded the anticipated reduction of flood risk in many scenarios and thus lead to negative average $N P V_{S}$ values. Similarly, flood zoning was very expensive, because it was applied to areas that were at risk of flooding at least once in 100 years. With an assumed property price of AUD 476,600 and unit flood damages of AUD 30,000 per property, flood zoning would be economically justified only for properties flooded every 5 to 10 years.

Nevertheless, the range of $N P V_{s}$ indicated by the minimal and maximal values shown in Table 3 also shows that the performance of adaptation strategies strongly depends on the considered scenario. Strategies such as rainwater harvesting or pipe increase that had negative $N P V_{S}$ on average would yield strongly positive $N P V_{S}$ in scenarios with strong urban growth and / or climate change, suggesting that strategies should be adapted along the pathway depending on the actual evolution of the drivers of flood risk.

Finally, in the worst case, the pathways considering only WSC master planning had a negative $N P V_{S}$ of AUD -700,000 despite an investment cost of 0 , indicating that changes in flood risk resulting from random variations in urban development also had a significant impact on $N P V_{S}$.

Table 3. Mean, maximum and minimum of net present value $N P V_{s}$ (Eq. 3) derived for the 9 different climate and population growth scenarios for the different adaptation options considered.

\begin{tabular}{|c|c|c|c|c|c|c|c|c|c|c|c|c|c|c|c|c|}
\hline Master plan & \multicolumn{16}{|c|}{ BAU } \\
\hline Flood- & \multicolumn{8}{|c|}{ NO } & \multicolumn{8}{|c|}{ YES } \\
\hline $\begin{array}{l}\text { Pipe } \\
\text { Increase }\end{array}$ & \multicolumn{4}{|c|}{ NO } & \multicolumn{4}{|c|}{ YES } & \multicolumn{4}{|c|}{ NO } & \multicolumn{4}{|c|}{ YES } \\
\hline $\begin{array}{l}\text { RWHT rate } \\
\text { [\%/year] }\end{array}$ & 0 & 1 & 3 & 5 & 0 & 1 & 3 & 5 & 0 & 1 & 3 & 5 & 0 & 1 & 3 & 5 \\
\hline $\begin{array}{l}\text { Mean } \mathrm{NPV}_{\mathrm{s}} \\
{\left[10^{6} \mathrm{AUD}\right]}\end{array}$ & 0.0 & 0.3 & - & $\begin{array}{c}- \\
0.5\end{array}$ & 9.8 & 10.5 & $\begin{array}{c}- \\
12.5\end{array}$ & $\begin{array}{c}- \\
12.9\end{array}$ & 90.1 & - & $\begin{array}{c}- \\
89.7\end{array}$ & - & $\begin{array}{c}- \\
115.8\end{array}$ & $\begin{array}{c}- \\
117.4\end{array}$ & $\begin{array}{c}- \\
116.1\end{array}$ & 119.9 \\
\hline $\begin{array}{l}\text { Max } \mathrm{NPV}_{\mathrm{s}} \\
{\left[10^{6} \mathrm{AUD}\right]}\end{array}$ & 0.0 & 8.6 & 5.2 & 8.2 & 9.1 & 8.7 & 7.1 & 7.7 & $\begin{array}{c}- \\
71.5\end{array}$ & - & - & $\begin{array}{c}- \\
78.2\end{array}$ & - & $\begin{array}{c}- \\
96.2\end{array}$ & 99.5 & $\begin{array}{c}- \\
101.5\end{array}$ \\
\hline $\begin{array}{l}\text { Min } \mathrm{NPV}_{\mathrm{s}} \\
{\left[10^{6} \mathrm{AUD}\right]}\end{array}$ & 0.0 & - & - & $\begin{array}{c}- \\
5.7\end{array}$ & 24.5 & $\begin{array}{c}- \\
26.1\end{array}$ & $\begin{array}{c}- \\
27.6\end{array}$ & 28.5 & - & $\begin{array}{c}- \\
108.4\end{array}$ & - & 107.9 & $\begin{array}{c}- \\
134.8\end{array}$ & $\begin{array}{c}- \\
136.3\end{array}$ & $\begin{array}{c}- \\
135.4\end{array}$ & $\mid-$ \\
\hline Master plan & & & & & & & & & & & & & & & & \\
\hline
\end{tabular}




\begin{tabular}{|l|c|c|c|c|c|c|c|c|c|c|c|c|c|c|c|c|}
\hline $\begin{array}{l}\text { Mean NPV } \\
{\left[10^{6} \text { AUD] }\right.}\end{array}$ & 11.0 & 10.3 & 9.2 & 8.3 & 7.5 & 8.7 & 10.2 & 11.0 & 89.6 & 90.1 & 89.0 & 90.6 & 116.2 & 116.9 & 116.5 & 117.7 \\
\hline $\begin{array}{l}\text { Max NPV } \\
{\left[10^{6} \text { AUD] }\right.}\end{array}$ & 29.0 & 27.7 & 29.4 & 25.8 & 16.2 & 15.4 & 14.2 & 13.4 & 66.8 & 64.9 & 68.6 & 68.5 & 91,2 & 90.1 & 93.9 & 91.8 \\
\hline $\begin{array}{l}\text { Min NPV } \\
{\left[10^{6} \text { AUD] }\right.}\end{array}$ & - & - & - & - & - & - & - & - & - & - & - & - & - & - & - & - \\
\hline
\end{tabular}

\section{Discussion}

\section{6}

537

538

539

540

541

542

543

544

545

546

547

548

549

550

551

552

553

554

555

556

557

558

559

560

561

562

563

564

565

566

567

568

569

\subsection{EFFiciency of AdAPTATion Strategies}

The results indicate that the implementation of a WSC master plan would be an efficient strategy for reducing flood risk over a variety of scenarios, while the implementation of rainwater harvesting measures provided only small reductions in expected damage. Flood zoning and increase in pipe capacity would reduce flood risk, but were too expensive to implement compared to the economic benefit they provide. Obviously, these results are very much subject to catchment characteristics and assumptions made during the simulations and cost assessments.

Our damage assessment was exemplary only and excluded, for example, indirect damages. Different assumptions on damage functions would lead to different absolute net present values, while we would still obtain similar results when comparing the efficiency of the different measures. The measures increase of pipe capacity and flood zoning were in this work implemented in a guideline oriented approach which led to an over-dimensioning of both measures. These measures could easily be improved in further simulation iterations. For flood zoning it is questionable if house prices in flood prone areas would actually remain constant as assumed in our study or drop because such areas would become less attractive for living, leading to a much reduced cost of the flood zoning policy.

The efficiency of rainwater harvesting measures strongly depends on the assumed tank size. Tank volumes of 10 or even $20 \mathrm{~m}^{3}$ are not unheard of in Australia and would certainly lead to better performance of this measure. In addition, the efficiency of rainwater harvesting measures strongly depends on the infiltration parameters assumed for pervious areas in the catchment. A higher contribution from pervious areas to the total runoff from the catchment will lead to a reduced effect of disconnecting impervious areas from the drainage network.

We noted that infrastructural flood adaptation measures such as increases in pipe capacity often have an almost immediate effect on the reduction of flood risk, while planning measures such as flood zoning or master planning would only gradually take effect over the planning horizon and thus result in smaller reductions of flood risk $E D^{*}$ over the planning horizon. However, this effect is somewhat balanced in the computation of $N P V_{S}$ because also investments for such measures are spread over the planning horizon.

\subsection{UNCERTAINTY AND LIMITATIONS OF THE SETUP}

\section{Scenario Definition}


While the simulation setup coupling DAnCE4Water and MIKEFLOOD aims to support decision makers in evaluating the robustness of different flood adaptation options in uncertain futures, the setup itself is subject to a number of uncertainties. First and foremost, we need to make assumptions about realistic ranges for future developments of climate and city structure. While this goes one step further than simply basing decision making on the assumed most probable future, we cannot explicitly handle uncertainties that we are not aware of (total ignorance in the terminology of (Walker et al., 2013)) or that we cannot quantify (level 5 uncertainty in (Walker et al., 2013)).

In our work, we have in all scenarios assumed continued population growth over the next 50 years. However, this assumption may prove wrong, for example, as a result of changes in economic development leading to changes in immigration patterns. In addition, different growth scenarios and developing societal preferences are likely to affect the choice of adaptation measures by, for example, limiting the funds available in the future. As demonstrated by (Lienert et al., 2015), such effects can be considered in the definition of scenarios and can be used to limit the bandwidth of potential developments that need to be considered.

\section{Urban Development Modelling}

The urban development simulations in DAnCE4Water currently focus strongly on the processes of urban densification of Australian cities building on observations over the last decades. However, densification may well lead to the evolution of different urban forms and a more compact city as noted by (Vermeer, 2014) and, other than assumed in our work, land use regulations are unlikely to remain static over the planning horizon and assumptions need to be made on their modification as demonstrated by (Malik et al., 2015).

Densification and urban sprawl into rural areas are expected to be affected by elements such as the location of infrastructures and topography. DAnCE4Water allows for the consideration of such elements in the form of, for example, rules for where development should occur, but they were not considered in our case study with a simple catchment, where the focus was on linking hydraulic and urban development modelling.

Urban development in different parts of the world would be expected to be subject to different drivers. For example, (Vermeer, 2014) point out the importance of central planning schemes in Beijing and of the development of slums in Mumbai. In Europe, several cities are subject to decreasing populations resulting in de-densification of the areas and re-developments often occur in formerly industrial areas. The consideration of such effects requires an analysis of the local development patterns and the considered effects need to be accepted by the involved stakeholders.

Finally, planning paradigms change after extreme flood or drought events. While it is in principle possible to include such effects in our simulation framework, little work was published to consider them in simulations of urban development.

\section{Flood Risk Assessment}

While we assumed that the flood risk assessment based on 1D-2D hydrodynamic simulations is a good approximation of the true flood response in the catchment, this assessment is subject to a number of uncertainties themselves. To name a few 
potential sources, there are effects from the parameters used to describe the coupling between 1D drainage network model and 2D surface models, from simplifications of the model description of drainage network and terrain surface and from uncertain parameters used to describe runoff from pervious areas. In the damage assessment, damage curves used for translating simulated flood hazard into damages are commonly subject to large uncertainty and the methodology used for assessing damages (for example thresholds on water depth where buildings are assumed flooded) will strongly impact the simulated risk. Finally, discount rates for the computation of expected damages depend on the local decision maker's preference. The impacts of such uncertainties on the preference of adaptation options in urban areas are unknown to date and require a systematic assessment as proposed with the “model chain” by (Apel et al., 2008).

Finally, our results showed that random variations in urban development can lead to quite significant differences in the simulated flood damage. For example, urban development could occur in more or less flood prone areas earlier or later along a simulated pathway. Similarly, a property subject to flood zoning measures would be resettled at random time points along a pathway, meaning that in some simulations strong reductions would occur earlier along the pathway than in others. In some cases, such effects had a stronger influence on our simulated expected damages, than the implementation of rainwater harvesting measures. It may well be desirable to include such uncertainties in the assessment, as they provide an idea of the effect of small variations in urban development on the simulated damages. For this purpose, it is important to ensure that the results actually are random, i.e., that different scenarios are based on independent simulations of urban development.

\subsection{SimULATION TIMES AND EXPERIMENTAL SETUP}

A main concern with implementing a framework based on an agent-based urban development model and a 1D-2D hydrodynamic model would be the simulation time and the numerical stability. We have performed the urban development and hydrodynamic simulations in separate cluster environments in Australia and Denmark and implemented a file based communication between the models via Dropbox. Simulation times were approximately 30 minutes for a period of 10 years in DAnCE4Water and 1 hour for simulating a single rain event in MIKE FLOOD. With a total of approximately 12,000 simulated rain events in MIKE FLOOD, such a setup is only feasible in a scientific context. Numerical stability is not a problem in DAnCE4Water by design. Performing automated hydrodynamic simulations without failures requires a careful preparation of the hydraulic model but was not a constraint for our work and was also demonstrated feasible in the application of 1D-2D modelling for online flood warning systems (Meneses et al., 2015).

The coupled simulation setup was in this work operated in a pathway oriented manner. For each combination of adaptation options and climate change and urban development scenario a separate set of simulations was performed. While this setup seems natural, it is also likely to be inefficient because hydrodynamic simulations were performed multiple times for very similar combinations of rainfall and number of households within a pathway and across different scenarios. The introduction of 
additional dimensions such as coastal flood risk or larger numbers of adaptation options would explode the computational requirements to infeasible levels.

On the other hand, our results indicate that the simulated damage values evolve rather smoothly along the dimensions rainfall and number of households in the catchment for a given adaptation approach (see supporting material). It is thus expected the computational effort can be limited with an experimental design where flood damage is only simulated for a few key combinations of rainfall and urban development and otherwise interpolated between the simulated results.

\subsection{OUTLOOK}

Computational requirements and the complexity of setting up the modelling framework and obtaining required input data are crucial issues for the application of our simulation framework in flood risk management practice. The computational requirements for hydraulic simulation can be reduced by applying simplified models. Approaches which can directly account for modifications of the terrain such as cellular automata (Ghimire et al., 2013; Shao et al., 2015; Viavattene and Ellis, 2013) or conceptual models which can be automatically generated from drainage network and terrain surface (CH2M, 2015; Wolfs et al., 2013) are preferable for this purpose. Similarly, urban development models can be difficult to set up if large amounts of socioeconomic data are required as input to the models. Current research therefore focuses on the development of approaches that can be employed with a minimum of input data (Mikovits et al., 2015b).

While our work presented the implementation of a coupled simulation framework, the results of this framework can flexibly be applied in different decision frameworks, assigning for example different probabilities to different scenarios of future developments (Borgomeo et al., 2014) or performing optimization of adaptation options along each pathway (Kwakkel et al., 2015) to identify robust combinations of adaptation. In the latter case, our setup would be used to simulate the effect of different land-use policies and flood adaptation measures on flood risk at a given time point, replacing the simple model applied by (Kwakkel et al., 2015). The computational effort related to such setups can be addressed through implementation in cluster environments as well as the application of surrogate models and experimental setups that minimize the number of simulations, for example, sequential setups described by (Kleijnen, 2015).

\section{CONCLUSIONS}

We have presented a framework for systematic assessment of flood risk adaptation options under uncertain futures, employing the agent-based urban development model DAnCE4Water and the 1D-2D hydrodynamic model MIKE FLOOD. We applied the setup to evaluate a variety of flood adaptation options in a case study in Melbourne, Australia and draw the following conclusions:

1. It is feasible to perform systematic assessment of flood adaptation options in an automated manner applying urban development and hydraulic models with high level of detail. 
2. The computational effort involved in running such a setup is significant. Attempts to reduce it may involve an optimized experimental design where flood damage surfaces are interpolated from selected sample points.

3. The new simulation setup provides damage assessments for a variety of combinations of adaptation options in a variety of potential futures. These results can be flexibly coupled to various decision making frameworks for choosing the preferred flood risk adaptation option.

4. The performance of adaptation strategies strongly depends on both, the considered climate and adaptation scenarios and on the other adaptation strategies implemented. Strategies that can be adapted to the observed developments along the planning horizon are thus often preferable over large one-off investments. Our setup can support the development of such strategies by simulating the effect of different measures in various scenarios.

5. Urban planning policies were an efficient measure to reduce flood risk in our case study. Guideline oriented approaches of increasing the pipe system to handle rain events with fixed return periods of 10 years and buying back properties in areas flooded at least once in 100 year resulted in investment cost which, for many climate and population growth scenarios, were not justified by the reduction in flood risk. Nevertheless, an ad-hoc definition of planning criteria is common practice in many countries.

6. The agent-based urban development model evolves the city in a random manner, developing properties at different locations and time points in different scenarios. Such variations can have quite significant influence on simulated flood damages.

7. While our setup flexibly assesses adaptation options for a variety of potential futures, we still need to make assumption on realistic ranges and paths for urban development and climate. Modelling thus provides the decision maker with an overview over which options are robust in which situations, but it does not provide a guarantee that a selected design will be functional.

8. The data needs for the urban development model are limited to layers of buildings, parcels and households and the setup is thus easy to implement in different cases. This property comes at the cost of excluding social processes from the model. Further, the model is specific for the case of densification of built-up residential areas. The application in other regions requires the implementation of alternative development procedures to model, for example, the redevelopment of city centres.

\section{ACKNOWLEDGEMENTS}

This research has been financially supported by the Australian Government through the CRC for Water Sensitive Cities. The catchment data were kindly provided by Melbourne Water. Vanessa Wong supported the data preparation and provided important input for the urban development scenarios.

\section{REFERENCES}

Aerts, J.C.J.H., Botzen, W.J.W., Emanuel, K., Lin, N., Moel, H. De, 2014. 
Evaluating Flood Resilience Strategies for Coastal Megacities. Science 344, 473-475.

Apel, H., Merz, B., Thieken, A.H., 2008. Quantification of uncertainties in flood risk assessments. International Journal of River Basin Management 6, 149-162.

Arnbjerg-Nielsen, K., 2012. Quantification of climate change effects on extreme precipitation used for high resolution hydrologic design. Urban Water Journal 9, 57-65.

Australia Institution of Engineers, 1987. Australian Rainfall and Runoff - A Guide to Flood Estimation, Revised Edition. Australia.

Bach, P.M., Mccarthy, D.T., Deletic, A., 2015. Can we model the implementation of water sensitive urban design in evolving cities? Water Science \& Technology $71,149$.

Bach, P.M., McCarthy, D.T., Urich, C., Sitzenfrei, R., Kleidorfer, M., Rauch, W., Deletic, A., 2013. A planning algorithm for quantifying decentralised water management opportunities in urban environments. Water Science \& Technology 68, 1857-1865.

Barreira González, P., Aguilera-Benavente, F., Gómez-Delgado, M., 2015. Partial validation of cellular automata based model simulations of urban growth: An approach to assessing factor influence using spatial methods. Environmental Modelling \& Software 69, 77-89.

Batty, M., 2009. Urban Modeling, in: Thrift, N., Kitchin, R. (Eds.), International Encyclopedia of Human Geography. Elsevier, Oxford, United Kingdom, pp. 51-58.

Borgomeo, E., Hall, J.W., Fung, F., Watts, G., Colquhoun, K., Lambert, C., 2014. Risk-based water resources planning: Incorporating probabilistic nonstationary climate uncertainties. Water Resources Research 50, 6850-6873.

CH2M, 2015. Flood Modeller - User Manual.

Cohen, B., 2004. Urban Growth in Developing Countries: A Review of Current Trends and a Caution Regarding Existing Forecasts. World Development 32, 23-51.

Crooks, A., Castle, C., Batty, M., 2008. Key challenges in agent-based modelling for geo-spatial simulation. Computers, Environment and Urban Systems 32, 417430.

CSIRO, Bureau of Meteorology, 2015. Climate Change in Australia Technical Report. Australia.

DHI, 2013. MIKE FLOOD - 1D-2D Modelling - User Manual.

Ehret, U., Götzinger, J., Bárdossy, A., Pegram, G., 2008. Radar based flood forecasting in small catchments, exemplified by the Goldersbach catchment, Germany. International Journal of River Basin Management 6, 323-329.

ESRI, 2012. ArcGIS Desktop: Release 10. 
French, R., Jones, M., 2012. Design rainfall temporal patterns in Australian Rainfall and Runoff : Durations exceeding one hour *. Australian Journal of Water Resources 16, 21-28.

GDAL Development Team, 2014. GDAL - Geospatial Data Abstraction Library, Version 1.11.0.

Gersonius, B., Nasruddin, F., Ashley, R., Jeuken, A., Pathirana, A., Zevenbergen, C., 2012. Developing the evidence base for mainstreaming adaptation of stormwater systems to climate change. Water research 46, 6824-35.

Ghimire, B., Chen, A.S., Guidolin, M., Keedwell, E.C., Djordjević, S., Savić, D. a., 2013. Formulation of a fast 2D urban pluvial flood model using a cellular automata approach. Journal of Hydroinformatics 15, 676.

Granger, C.W.J., Jeon, Y., 2007. Long-term forecasting and evaluation. International Journal of Forecasting 23, 539-551.

Hall, J., Arheimer, B., Borga, M., Brázdil, R., Claps, P., Kiss, A., Kjeldsen, T.R., Kriaučūnienè, J., Kundzewicz, Z.W., Lang, M., Llasat, M.C., Macdonald, N., McIntyre, N., Mediero, L., Merz, B., Merz, R., Molnar, P., Montanari, A., Neuhold, C., Parajka, J., Perdigão, R.A.P., Plavcová, L., Rogger, M., Salinas, J.L., Sauquet, E., Schär, C., Szolgay, J., Viglione, A., Blöschl, G., 2014. Understanding flood regime changes in Europe: A state-of-the-art assessment. Hydrology and Earth System Sciences 18, 2735-2772.

Handmer, J., Read, C., Percovich, O., Reed, C., Percovich, O., 2003. Disaster Loss Assessment Guidelines, Assessment. Dickson, Australia.

Henonin, J., Hongtao, M., Zheng-Yu, Y., Hartnack, J., Havnø, K., Gourbesville, P., Mark, O., 2015. Citywide multi-grid urban flood modelling: the July 2012 flood in Beijing. Urban Water Journal 12, 52-66.

Hinkel, J., Lincke, D., Vafeidis, A.T., Perrette, M., Nicholls, R.J., Tol, R.S.J., Marzeion, B., Fettweis, X., Ionescu, C., Levermann, A., 2014. Coastal flood damage and adaptation costs under 21st century sea-level rise. Proceedings of the National Academy of Sciences of the United States of America 111, 32927.

Hoymann, J., 2010. Spatial allocation of future residential land use in the Elbe River Basin. Environment and Planning B: Planning and Design 37, 911-928.

Huong, H.T.L., Pathirana, A., 2013. Urbanization and climate change impacts on future urban flood risk in Can Tho city, Vietnam. Hydrology and Earth System Sciences 17, 379-394.

Kleijnen, J.P.C., 2015. Design and analysis of simulation experiments, 2nd ed. Springer, Tilburg, The Netherlands.

Kwakkel, J., Haasnoot, M., Walker, W.E., 2015. Developing dynamic adaptive policy pathways: a computer-assisted approach for developing adaptive strategies for a deeply uncertain world. Climatic Change 132, 373-386.

Lienert, J., Scholten, L., Egger, C., Maurer, M., 2015. Structured decision-making for sustainable water infrastructure planning and four future scenarios. EURO 
Madsen, H., Lawrence, D., Lang, M., Martinkova, M., Kjeldsen, T.R., 2014. Review of trend analysis and climate change projections of extreme precipitation and floods in Europe. Journal of Hydrology 519, 3634-3650.

Malik, A., Crooks, A., Root, H., Swartz, M., 2015. Exploring creativity and urban development with agent-based modeling. Journal of Artificial Societies and Social Simulation 18, 1-19.

Matthews, R.B., Gilbert, N.G., Roach, A., Polhill, J.G., Gotts, N.M., 2007. Agentbased land-use models: a review of applications. Landscape Ecology 22, 14471459.

Mendelsohn, R., 2006. Critique of the Stern Report, A. Regulation 42-46.

Meneses, E.J., Löwe, R., Brødbæk, D., Courdent, V., Petersen, S.O., 2015. SURFF Operational Flood Warnings for Cities Based on Hydraulic 1D-2D Simulations and NWP, in: Proceedings of the 10th International Conference on Urban Drainage Modelling (UDM). Québec, Canada.

Merz, B., Aerts, J.C.J.H., Arnbjerg-Nielsen, K., Baldi, M., Becker, A., Bichet, A., Blöschl, G., Bouwer, L.M., Brauer, A., Cioffi, F., Delgado, J.M., Gocht, M., Guzzetti, F., Harrigan, S., Hirschboeck, K., Kilsby, C., Kron, W., Kwon, H.H., Lall, U., Merz, R., Nissen, K., Salvatti, P., Swierczynski, T., Ulbrich, U., Viglione, A., Ward, P.J., Weiler, M., Wilhelm, B., Nied, M., 2014. Floods and climate: Emerging perspectives for flood risk assessment and management. Natural Hazards and Earth System Sciences 14, 1921-1942.

Merz, B., Hall, J., Disse, M., Schumann, A., 2010. Fluvial flood risk management in a changing world. Natural Hazards and Earth System Sciences 10, 509-527.

Merz, B., Vorogushyn, S., Lall, U., Viglione, A., Bloeschl, G., 2015. Charting unknown water - on the role of surprise in flood risk assessment and management. Water Resources Research 51, 6399-6416.

Mikovits, C., Rauch, W., Kleidorfer, M., 2015a. A dynamic urban development model designed for purposes in the field of urban water management. Journal of Hydroinformatics 17, 390-403.

Mikovits, C., Rauch, W., Kleidorfer, M., 2015b. A dynamic urban development model designed for purposes in the field of urban water management. Journal of Hydroinformatics 17, 390-403.

Muis, S., Güneralp, B., Jongman, B., Aerts, J.C.J.H., Ward, P.J., 2015. Flood risk and adaptation strategies under climate change and urban expansion: A probabilistic analysis using global data. The Science of the total environment 538, 445-457.

Muller, M., 2007. Adapting to climate change: water management for urban resilience. Environment and Urbanization 19, 99-113.

Olsen, A.S., Zhou, Q., Linde, J.J., Arnbjerg-Nielsen, K., 2015. Comparing methods of calculating expected annual damage in urban pluvial flood risk assessments. Water 7, 255-270. 
Olsen, J.R., Lambert, J.H., Haimes, Y.Y., 1998. Risk of extreme events under nonstationary conditions. Risk Analysis 18, 497-510.

Poelmans, L., Rompaey, A. Van, Ntegeka, V., Willems, P., 2011. The relative impact of climate change and urban expansion on peak flows: A case study in central Belgium. Hydrological Processes 25, 2846-2858.

Poelmans, L., Van Rompaey, A., 2010. Complexity and performance of urban expansion models. Computers, Environment and Urban Systems 34, 17-27.

Prudhomme, C., Wilby, R.L., Crooks, S., Kay, A.L., Reynard, N.S., 2010. Scenarioneutral approach to climate change impact studies: Application to flood risk. Journal of Hydrology 390, 198-209.

Russo, B., Sunyer, D., Velasco, M., Djordjević, S., 2015. Analysis of extreme flooding events through a calibrated $1 \mathrm{D} / 2 \mathrm{D}$ coupled model: the case of Barcelona (Spain). Journal of Hydroinformatics 17, 473-492.

Sekovski, I., Armaroli, C., Calabrese, L., Mancini, F., Stecchi, F., Perini, L., 2015. Coupling scenarios of urban growth and flood hazards along the EmiliaRomagna coast (Italy). Natural Hazards and Earth System Sciences 15, 23312346.

Semadeni-Davies, A., Hernebring, C., Svensson, G., Gustafsson, L.G., 2008. The impacts of climate change and urbanisation on drainage in Helsingborg, Sweden: Combined sewer system. Journal of Hydrology 350, 100-113.

Shao, Q., Weatherley, D., Huang, L., Baumgartl, T., 2015. RunCA: A cellular automata model for simulating surface runoff at different scales. Journal of Hydrology 529, 816-829.

Stedinger, J.R., 1997. Expected Probability and Annual Damage Estimators. Journal of Water Resources Planning and Management 123, 125-135.

Stern, N., 2007. The Economics of Climate Change - The Stern Review, 1st ed. Cambridge University Press, Cambridge, United Kingdom.

Stern, N., 2016. Current climate models are grossly misleading. Nature 530, 407409.

Sun, Y., Solomon, S., Dai, A., Portmann, R.W., 2007. How often will it rain? Journal of Climate 20, 4801-4818.

Sunyer, M.A., Rosbjerg, D., Madsen, H., Luchner, J., Arnbjerg-Nielsen, K., 2014. Comparison of different statistical downscaling methods to estimate changes in hourly extreme precipitation using RCM projections from ENSEMBLES. International Journal of Climatology.

The State of Victoria - Department of Transport Planning and Local Infrastructure, 2014. Plan Melbourne. Melbourne, Australia.

Urich, C., Rauch, W., 2014. Exploring critical pathways for urban water management to identify robust strategies under deep uncertainties. Water research 66C, 374-389.

USACE, 1989. EAD - Expected Annual Flood Damage Computation - User’s 
Manual.

USACE, 1992. Guidelines for Risk and Uncertainty Analysis in Water Resources Planning. Fort Belvoir, VA, United States.

Vermeer, D., 2014. Economic and urban growth models. Exeter, United Kingdom.

Viavattene, C., Ellis, J.B., 2013. The management of urban surface water flood risks: SUDS performance in flood reduction from extreme events. Water Science and Technology 67, 99-108.

Waddell, P., 2002. UrbanSim - Modeling urban development for land use, transportation, and environmental planning. Journal of the American Planning Association 68, 297-314.

Walker, W.E., Lempert, R., Kwakkel, J., 2013. Deep Uncertainty. Encyclopedia of Operational Research and Management Science.

Walker, W.E., Rahman, S.A., Cave, J., 2001. Adaptive policies, policy analysis, and policy-making. European Journal of Operational Research 128, 282-289.

Wolfs, V., Villazon, M.F., Willems, P., 2013. Development of a semi-automated model identification and calibration tool for conceptual modelling of sewer systems. Water Science and Technology 68, 167-175.

Wong, V., 2014. An investigation into infrastructure system response to climate change adaptation strategies in the Scotchman's Creek Catchment. Monash University, Melbourne, Australia.

Zhou, Q., Mikkelsen, P.S., Halsnæs, K., Arnbjerg-Nielsen, K., 2012. Framework for economic pluvial flood risk assessment considering climate change effects and adaptation benefits. Journal of Hydrology 414-415, 539-549.

Zhu, T., Lund, J.R., Jenkins, M.W., Marques, G.F., Ritzema, R.S., 2007. Climate change, urbanization, and optimal long-term floodplain protection. Water Resources Research 43, 1-11.

\section{Figure CAPTIONS}




\section{Supporting Material for “Assessment of Urban Pluvial Flood Risk and Efficiency of Adaptation Options Through Simulations - A New Generation of Urban Planning Tools”}

\section{S1 Modelling SetuP}

\section{S1.1 HydRAULIC FLOOD ModELLING}

The Scotchman's Creek catchment is drained through separate pipe systems for stormwater and wastewater. We were provided with a highly detailed model of the stormwater drainage network by Melbourne Water. The model contained a total of 1,300 links with diameters of $0.1 \mathrm{~m}$ and higher. The catchment area was divided into 1,500 subcatchments for which runoff hydrographs were computed. The hydrographs were then used as input to the nearest manhole in the stormwater pipe system. Impervious area percentages in the subcatchments were computed from building footprints and road polygons provided by the utility company Melbourne Water. Based on an analysis of aerial imagery (Wong, 2014), the impervious roof area within a subcatchment was increased by $15 \%$ to account for sealed areas such as terraces or private parking. Rainfall on impervious areas was assumed to be subject to an initial loss of $0.4 \mathrm{~mm}$ and otherwise to be fully transformed into runoff.

Infiltration from unsealed areas was described using Horton's equation (Chow et al., 1988). The duplex soil types mostly present in the catchment (The State of Victoria Department of Economic Development Jobs Transport and Resources, 2016) have a sharp contrast in texture between top and subsoil, typically with less permeable layer in the subsoil. We thus assumed an initial loss of $6 \mathrm{~mm}$ for runoff from pervious areas and initial and final infiltration capacities corresponding to loamy soils with $36 \mathrm{~mm} / \mathrm{h}$ and $3.6 \mathrm{~mm} / \mathrm{h}$, respectively.

Digital elevation information was available from Geoscience Australia with a horizontal resolution of 5m (Geoscience Australia, 2015) and used to model surface water flow in MIKE FLOOD using a standard raster-based approach. Design rainfalls were extracted from Australian guidelines (Australia Institution of Engineers, 1987; French and Jones, 2012).

\section{S1.2 URBAn DeVELopMent ModeLling}

DAnCE4Water's urban and infrastructure development component evolves the urban environment at parcel level detail under different adaptation options. The process is driven by population projections which define the rate at which new households appear in the catchment. As described in the article, urban development is modelled as an interaction between the three actors city council, developers and households. In short, the city council defines zones where certain forms of development occur, developers create new buildings if there is a demand for housing (see (Urich and 
Rauch, 2014)) and households move into empty residential units. The agents' actions are manifested in the model using procedural modelling algorithms.

In practice, the user needs to define zoning policies that are implemented as rules in the model and rules for whether developers should preferably develop certain areas of the city, depending on, for example, distance to transport routes, service centres or green areas.

Urban development is then implemented by (re-)developing parcels. New households appear in the catchment on a yearly basis based on the population projection. To satisfy the housing demand, developers select a number of parcels to develop based on their "attractiveness" (Stevens et al., 2007). In zones where infill development occurs, parcels are marked as available for subdivision. Subsequently, procedural algorithms (Vanegas et al., 2012) are applied to split each parcel in such a way, that as many new parcels as possible are generated, while the area of each new parcel remains above a user-defined threshold. Similarly, in zones where apartment blocks should be developed, existing parcels are merged to obtain a minimal parcel size. Existing building footprints are replaced by either template footprints or modelled building footprints (Müller et al., 2006).

For the Scotchman's Creek case study, we have modelled urban development over a planning horizon of 50 years in 5 year intervals. Parcels were subdivided to a minimum area of $300 \mathrm{~m}^{2}$ during parcel splitting, while a minimum parcel size of $1,800 \mathrm{~m}^{2}$ was assumed for apartment blocks. Table S 1 summarizes the components included in the urban development model in our case study. Table $\mathrm{S} 2$ summarizes the interactions between the agents and the development parameters applied. Technically, the urban development model is implemented as GIS layers in a SQLITE database.

Table S 1. Components of city database model. Components are linked through attributes in the corresponding GIS layers.

\begin{tabular}{l|l|l|l}
\hline Component & $\begin{array}{l}\text { Abbrev- } \\
\text { iation }\end{array}$ & $\begin{array}{l}\text { Links to } \\
\text { other com- } \\
\text { ponents }\end{array}$ & Source \\
\hline Households & H & U & $\begin{array}{l}\text { Census data stochastically } \\
\text { disaggregated and assigned to U }\end{array}$ \\
\hline Residential Units & U & B & $\begin{array}{l}\text { Census data stochastically } \\
\text { disaggregated and assigned to B }\end{array}$ \\
\hline Buildings & B & P & Melbourne Water \\
\hline Parcels & P & & Cadastral maps \\
\hline Rainwater Harvesting & RWHT & P & - \\
\hline $100 y$ flood zone & FZ & P & Melbourne Water \\
\hline
\end{tabular}


Table S 2. Actors and rules used to implement land use policies in the urban development model.

\begin{tabular}{|c|c|c|}
\hline Agent & \multicolumn{2}{|c|}{ Rule } \\
\hline City Council & \multicolumn{2}{|c|}{$\begin{array}{l}\text { Impose zoning regulation on parcel. Subdivide parcel } \\
\text { according to zoning regulation. }\end{array}$} \\
\hline Urban Developer & \multicolumn{2}{|c|}{$\begin{array}{l}\text { Select parcel with highest "attractiveness" }\left(\alpha_{p}\right) \text { and build } \\
\text { buildings with } \mathrm{n} \text { residential units according to zoning } \\
\text { regulation. Repeat until demand for residential units } \Delta U_{t} \text { is } \\
\text { fulfilled. }\end{array}$} \\
\hline Household & \multicolumn{2}{|c|}{$\begin{array}{l}\text { If unplaced move into residential unit with highest } a_{p} \text {. } \\
\text { Repeat until all } \Delta H_{t} \text { are placed or until all residential units } \\
\text { are filled. }\end{array}$} \\
\hline Parameter & \multicolumn{2}{|c|}{ Description } \\
\hline Vacancy (\%) & \multicolumn{2}{|c|}{$v_{t}=\frac{\sum U_{t}}{\sum H_{t}}-1\left(=\frac{\text { no.of residential units }}{\text { no.of households }}-1\right)$} \\
\hline $\begin{array}{l}\text { Demand Residential } \\
\text { Units }\end{array}$ & $\Delta U_{t}=\left(v-v_{t}\right) \sum U_{t}$ & $v \ldots$ Target vacancy $(3 \%)$ \\
\hline $\begin{array}{l}\text { Parcel Attractiveness } \\
\left(\mathrm{m}^{-1}\right)\end{array}$ & $a_{p} \sim U([0,1])$ & $\begin{array}{l}\text { Uniformly distributed based } \\
\text { on (Wong, 2014) }\end{array}$ \\
\hline Unplaced Households & $\Delta H_{t}=H_{t-1} \cdot h+H_{R, t}$ & $\begin{array}{l}h \ldots \text { Household growth rate } \\
(0.004,0.008 \text { or } 0.012)\end{array}$ \\
\hline & & $\begin{array}{l}H_{R} \ldots \text { Relocated households } \\
\text { from flood zone (see Section } \\
\text { S3) }\end{array}$ \\
\hline
\end{tabular}

Figure S 1 and Figure S 2 illustrate the development zoning implemented in the two considered scenarios. In the BAU scenario, densification through parcel splitting at random locations was implemented in the whole catchment on Medium Density Residential zones. In the WSC scenario, apartment blocks containing 15 residential units each were developed along transport corridors. Parcel splitting was implemented in Medium Density Residential Zones in a limited part of the catchment, while the urban form was assumed unchanged in the remaining part of the catchment. Evidently, for the same population the BAU scenario lead to a significantly more dense development pattern than the WSC scenario.

As discussed in the article, the implemented urban development procedures provide a realistic image of the processes occurring in built-up areas of Australian cities. To apply the model to a different context they require an analysis of the dominant processes in other case studies and an extension of the modelling framework with suitable development rules. 


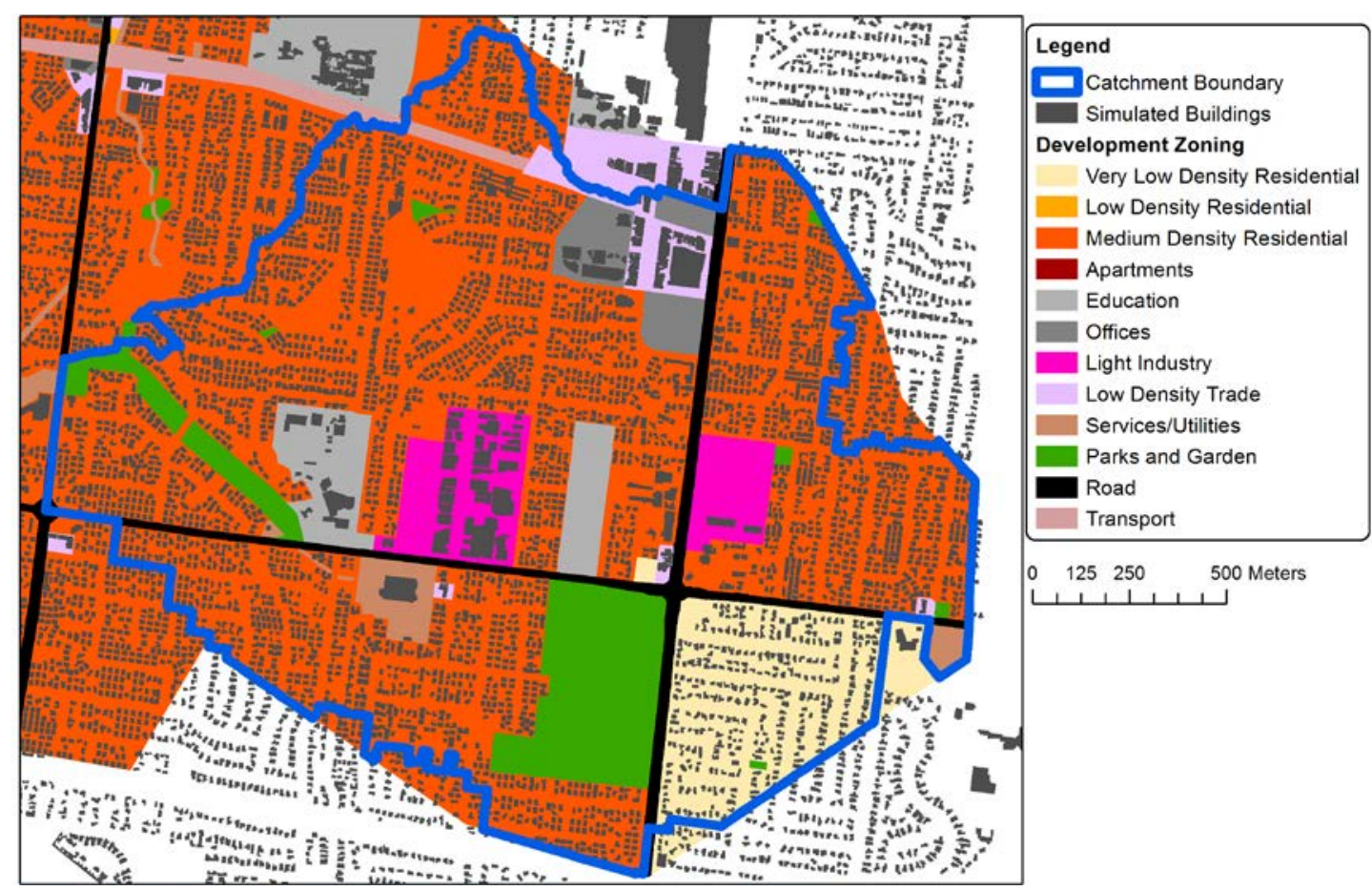

Figure S 1. Development zoning and simulated urban development until 2060 in the BAU scenario for a population growth rate of $0.8 \%$ year
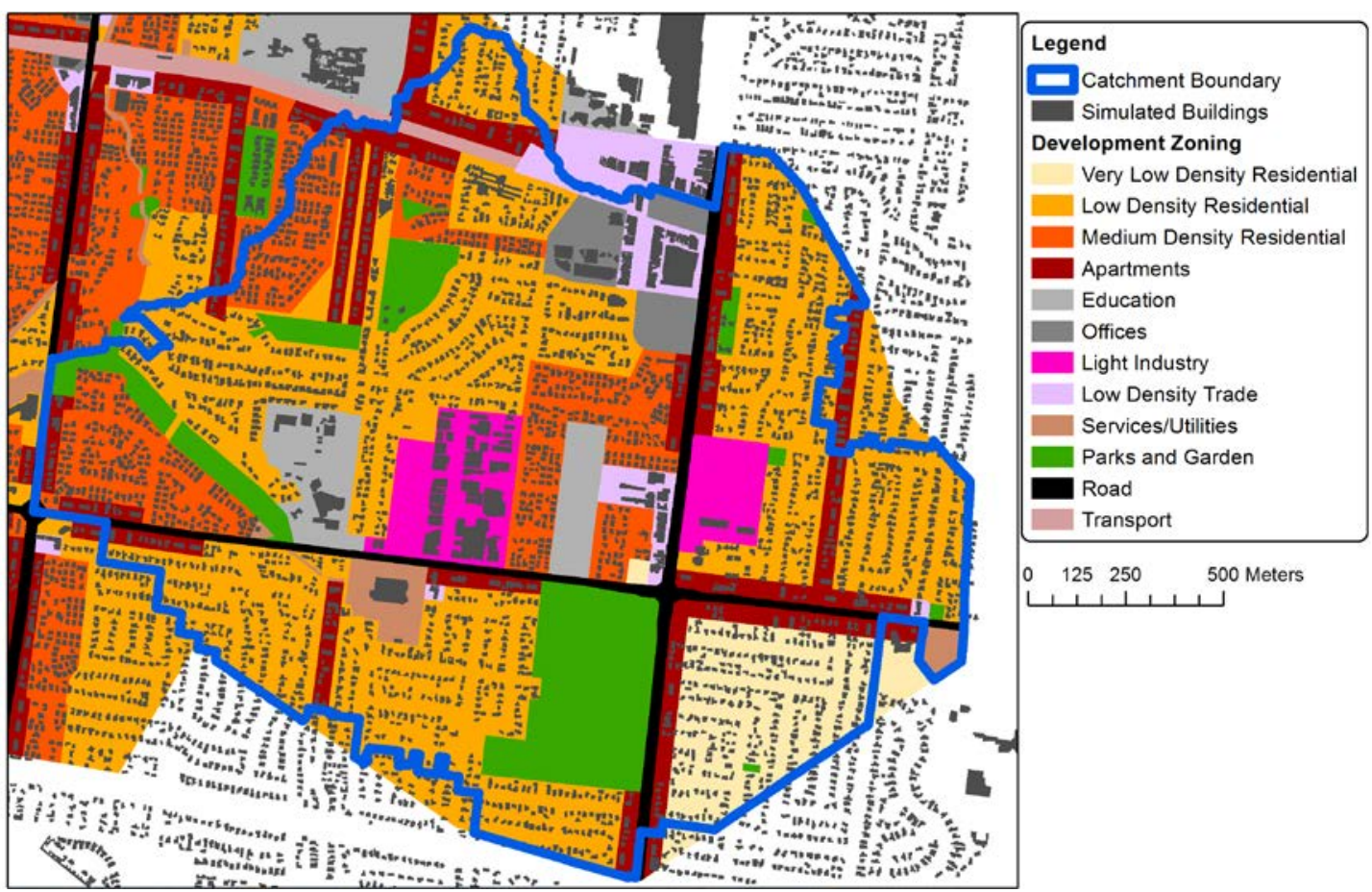

$0 \quad 125250 \quad 500$ Meters

Figure S 2. Development zoning and simulated urban development until 2060 in the WSC scenario for a population growth rate of $0.8 \%$ year 


\section{S2 IMPLEMENTATION OF FLOOD AdAPTATION MEASURES}

In our article, we have considered a number of structural and non-structural measures that aim at reducing flood risk in the catchment. To illustrate the potential of the coupled software framework, we considered a spectrum of options ranging from the implementation of urban planning policies to classical engineering solutions.

The considered options were:

1. Master plans controlling the form of urban development.

As discussed above, two different master plans were implemented by defining different development zonings. The main difference between the two is that a less dense urban development pattern was implemented in the WSC scenario along with the construction of multi-storey buildings along transport corridors.

2. Flood zoning.

This strategy focused on reducing the exposure to flood hazards through a buyback of properties. Buildings which were at risk of flooding more often than once in 100 years in the status situation in 2010 would be assigned a chance of 3\% to be bought back during any year of the planning horizon. Buildings on the parcel were removed and the parcel converted into a green area in the urban development model. The households were relocated within the catchment.

3. Large scale implementation of rainwater harvesting facilities (RWHT). Due to the positive effects on drinking water consumption, this is an often considered strategy amongst Australian stakeholders to reduce water demand. Tank sizes vary, but typically range between 1 and 10m3 (National Water Commission, 2008). We considered four scenarios, where rainwater tanks were implemented randomly throughout the catchment in the urban development model. The scenarios had different implementation rates of 0,1 , 3 and 5\% per year. This means that for each year during the planning horizon any building without rainwater harvesting would have a chance between 0 and $5 \%$ to have a rainwater tank implemented.

In the modelling setup, DAnCE4Water would randomly select buildings where RWHT should be implemented at different time points. When updating the MIKE FLOOD rainfall-runoff model (MOUSE) based on the simulated building footprints (see Section 2.5 in the paper), the roof area of a building with rainwater tank was considered as pervious area during runoff computation. This approach was easily implemented because the building could simply be neglected in the computation of impervious area percentages for the concerned sub-catchment. It was motivated by the fact that we did not have access to detailed information on typical rain water tank sizes in the area. Total effective rainfall during the considered design storms was typically approximately $25 \mathrm{~mm}$ smaller for pervious areas than for impervious areas. Approximately $18 \mathrm{~mm}$ of this reduction occurred in the beginning of the rain event, i.e., before any runoff occurred. Considering a median roof area of $165 \mathrm{~m} 2$ in the catchment, this reduction in runoff would correspond to a typical effective rainwater tank size of 3 to $4 \mathrm{~m} 3$

4. Increase in pipe capacity.

In this strategy the dimension of the stormwater pipes was increased until 
flooding no longer occurred more than once in 10 years anywhere in the catchment in the status situation in 2010. The strategy was implemented in the model simply by replacing the original pipe network by a (manually) modified pipe network in those simulations where an increase of pipe capacity should be considered. This approach is generic and would also allow for the consideration of other modifications in the hydraulic model, i.e., modified models for different adaptation options are developed manually and then inserted into the model as "templates" in combination with various other adaptation measures.

We performed an assessment of the expected investment cost for each adaptation measure, as well as potential benefits each measure could yield in addition to the reduction in flood risk. An overview of the considered cost and benefits is provided in Table S 3. 
Table S 3. Investment cost and additional benefits considered for the different flood adaptation strategies considered

\begin{tabular}{|l|l|l|}
\hline Flood Adaptation Strategy & Investment Cost $I_{s, t}$ & Additional Benefits $B_{s, t}$ \\
\hline 1. Master Planning & & \\
\hline 2. Flood Zoning & $\begin{array}{l}\text { AUD 476,600 per bought back } \\
\text { property, corresponding to } \\
\text { Melbourne median house price } \\
\text { in 2011 (Stapledon, 2012) }\end{array}$ & \\
\hline 3. Rainwater Harvesting & $\begin{array}{l}\text { Installation cost: } \\
\text { Tank installation: AUD 2170 } \\
\text { Pump installation: AUD 355 } \\
\text { replacement of pumps every 10 } \\
\text { years, replacement of tanks } \\
\text { every 25 years }\end{array}$ & $\begin{array}{l}\text { AUD 99 /year for each installed } \\
\text { rainwater tank, assuming a } \\
\text { drinking water price of 3 } \\
\text { AUD/cbm (South East Water, } \\
\text { 2016) and an annual reduction } \\
\text { in drinking water consumption } \\
\text { of 33cbm per installed } \\
\text { rainwater tank (Moglia et al., } \\
\text { 2015) }\end{array}$ \\
& $\begin{array}{l}\text { Running cost: } \\
\text { 20 AUD/year fixed cost } \\
\text { 0.05 AUD/cbm of rainwater } \\
\text { usage } \\
\text { (cost taken from (Tam et al., } \\
\text { 2010) }\end{array}$ & - \\
\hline 4. Increase in Pipe Capacity & $\begin{array}{l}\text { AUD 32,500,000 assumed as a } \\
\text { one-off investment in the first } \\
\text { year of the planning horizon for } \\
\text { modifying 8300m of existing } \\
\text { pipes. Considering the cost of } \\
\text { breaking up bitumen, trenching } \\
\text { and backfilling, installing new } \\
\text { pipes and manholes and paving } \\
\text { (Rawlinsons, 2011) }\end{array}$ & \\
\hline
\end{tabular}




\section{S3 Flood Damage Evaluation}

The 1D-2D hydrodynamic simulations result in raster layers of water depths simulated in the different pixels for different time points during a rain event. For planning purposes, the simulated water depths should be translated into damage values for each event. A variety of damage assessment frameworks with differing levels of complexity were suggested both internationally (Hammond et al., 2015; Merz et al., 2010; Velasco et al., 2015) and in Australia (Middelmann-Fernandes, 2010; Office of Environment and Heritage, 2007; Smith and Greenaway, 1994;

Sturgess, 2000).

The purpose of this article is to illustrate the coupled urban development and hydrodynamic flood modelling framework rather than provide an exact damage assessment. Considering the variety of different damage assessment methods developed in Australia, we therefore resorted to a unit cost approach focusing on direct cost resulting from damages to buildings and roads for illustrative purposes, applying damage values provided in (Handmer et al., 2003) after inflation adjustment from the year 1999 to 2011 (Reserve Bank of Australia, 2016):

- Buildings were assumed to incur a damage of AUD 29,742 if the maximal simulated water level in any pixel next to a building exceeded $0.3 \mathrm{~m}$.

- Flooded roads were assumed to incur a damage of AUD 3.63 per sqm of road where the maximal simulated water level exceeded $0.3 \mathrm{~m}$. The damage value was derived from the per $\mathrm{km}$ road length damages provided in (Handmer et al., 2003) assuming an average width of $7.5 \mathrm{~m}$ for minor roads and $24 \mathrm{~m}$ for major roads. 


\section{S4 VARIATION OF FLOOD DAMAGES AS A FUNCTION OF RAINFALL AND URBAN POPULATION}

We have analysed the simulated flood damages in single rain events for different combinations of total rainfall and population in the catchment. The number of households living in the catchment was used to describe the current population in this analysis. The results are shown in Figure S 3 to Figure S 5 for business as usual (BAU) simulations without adaptation options, for simulations where a water sensitive cities (WSC) master plan was implemented as the only adaptation option and for simulations where an increase in pipe capacity was implemented as the only adaptation option. The plots include a surface to indicate the overall trends. The surface was fitted using ordinary kriging in the R-package GSTAT (Pebesma, 2004). A Gaussian variogram structure was assumed and the kriging parameters sill, range and measurement error were estimated for each of the datasets using weighted least squares, while the nugget parameter was set to 0 to obtain a smooth surface (Pebesma, 2004).

It is evident that increasing rainfall and household numbers lead to an increase in the simulated flood damage for the BAU simulations and the simulations involving an increased pipe capacity. If urban development simulations were performed along a WSC master plan, increasing household numbers would not lead to an increase in flood damage, because the increasing number of households in the catchment would be accommodated in apartment blocks. This supports the results of Figure 6 in the article, where $E A D_{t}$ was observed to be less sensitive to urban development when implementing a WSC master plan. Increasing the capacity of the drainage network led to a shift of the damage surface, where flood damages were generally lower than in the situation without flood adaptation but increased with the number of households and the rain intensity.

Note that, given a fixed combination of adaptation measures, the damage surfaces evolved rather smoothly along the dimensions rainfall and number of households. This suggests that flood damages for different scenarios could be derived in a more efficient manner by performing a limited number of coupled urban development hydraulic flood simulations for each adaptation option, and then interpolating damages for other values of rainfall and number of households in between the simulated results. 


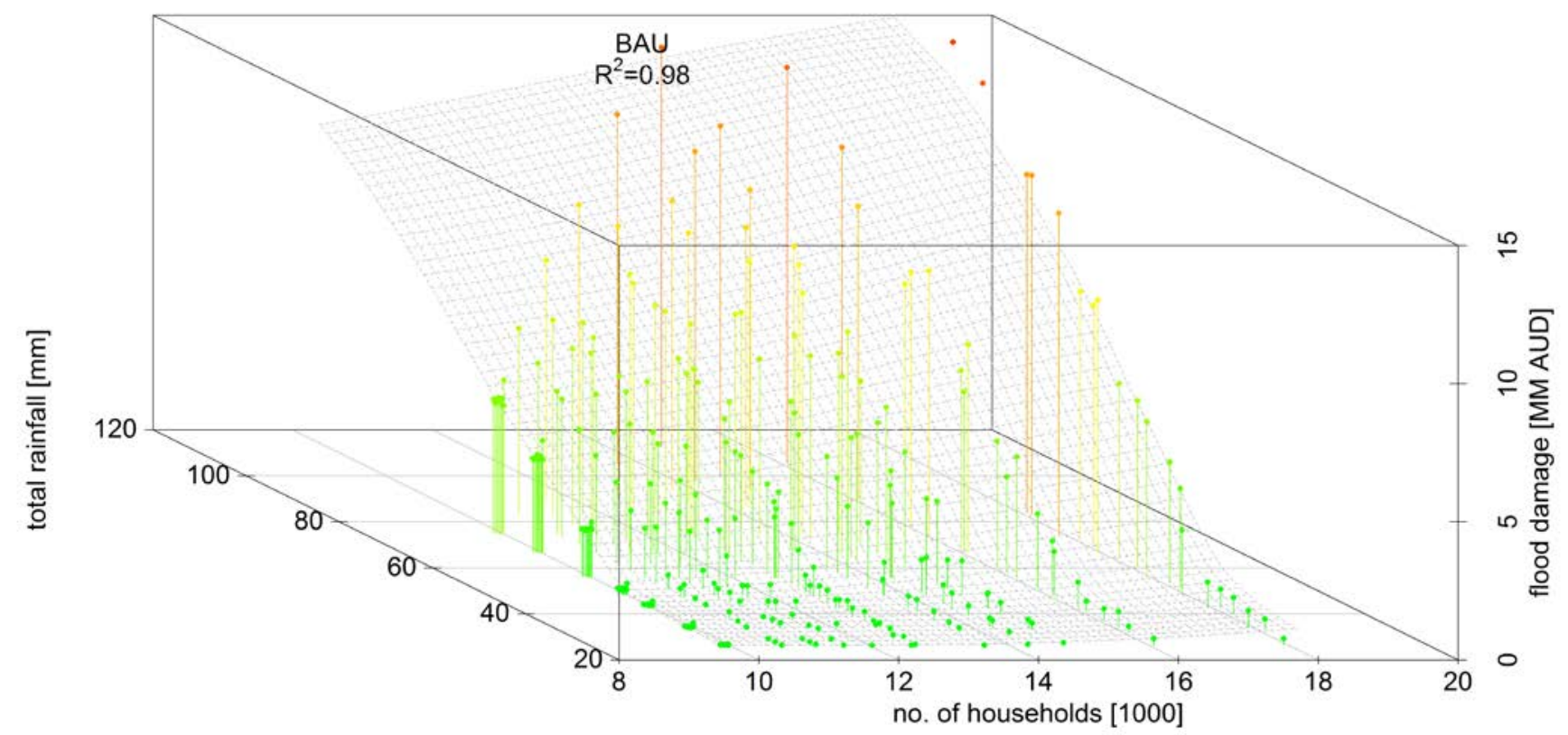

Figure S 3. Simulated flood damages for different combinations of rainfall and population growth on a single event basis in the business as usual scenario (BAU) without implementation of any adaptation options.

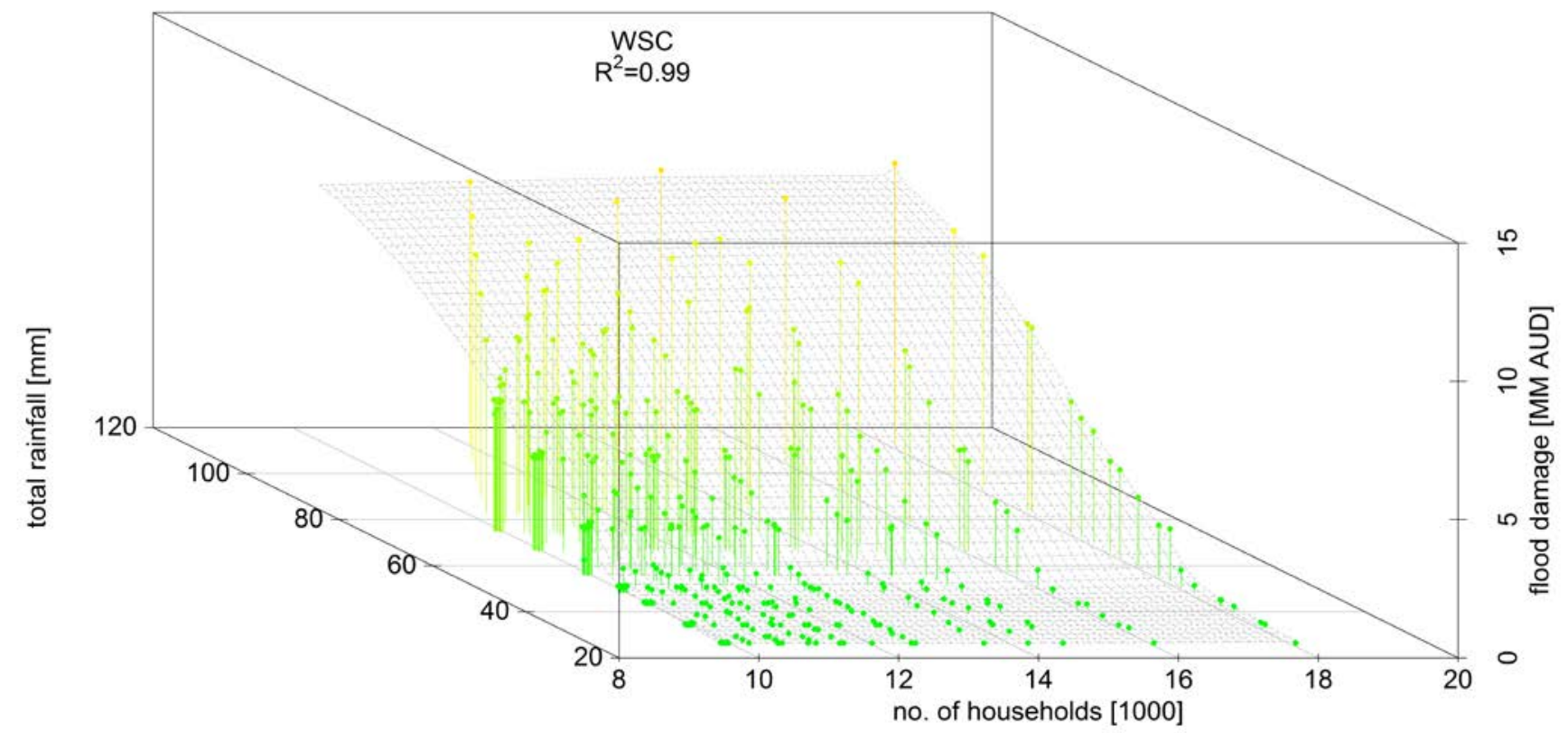

Figure S 4. Simulated flood damages for different combinations of rainfall and population growth on a single event basis when implementing a water sensitive city master plan (WSC) focusing on the development on apartment blocks. 


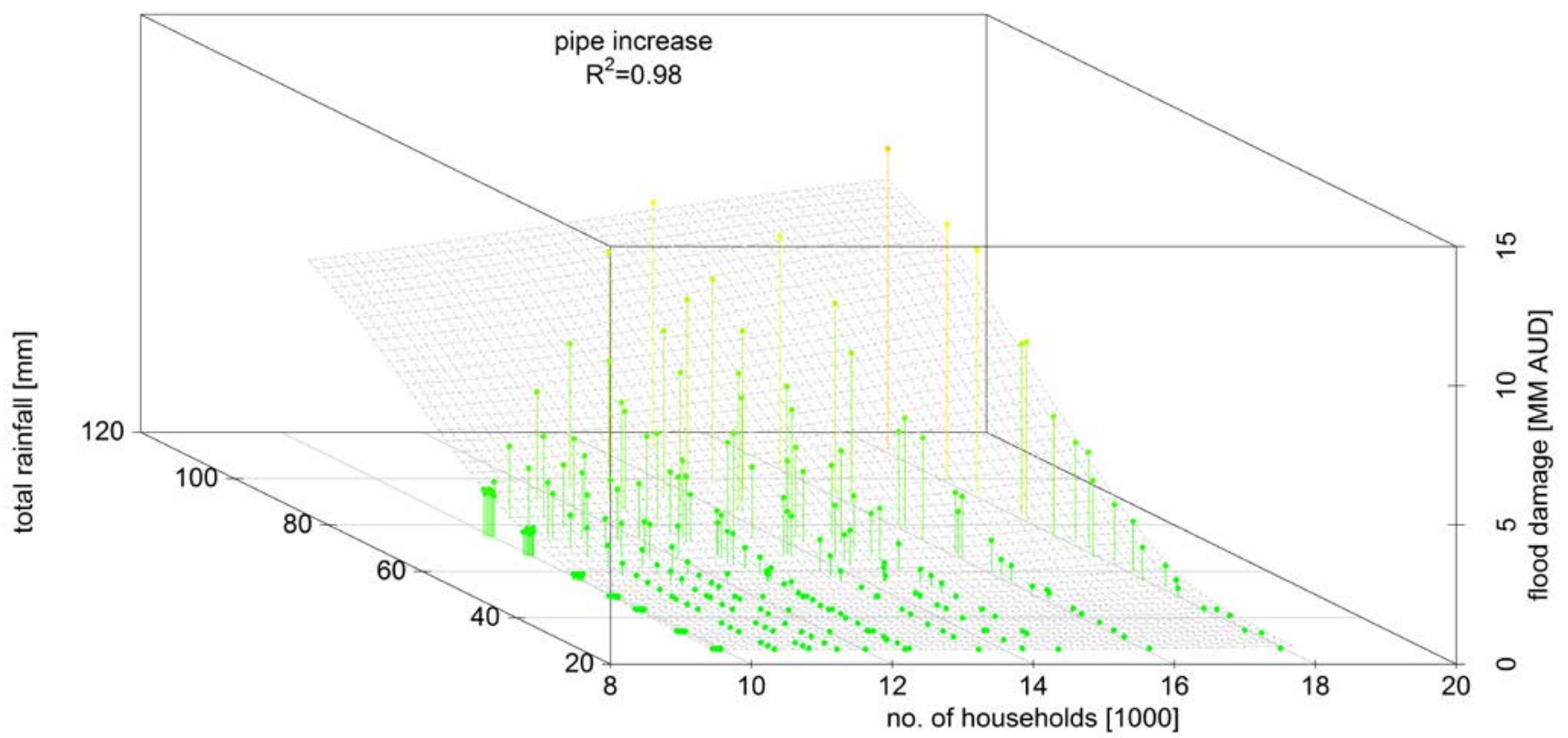

Figure S 5. Simulated flood damages for different combinations of rainfall and population growth on a single event basis when increasing the pipe diameters in the catchment (pipe increase) 


\section{S5 REFERENCES}

Australia Institution of Engineers, 1987. Australian Rainfall and Runoff - A Guide to Flood Estimation, Revised Edition. Australia.

Chow, V.T., Maidment, D.R., Mays, L.W., 1988. Applied hydrology, 1st ed. McGraw-Hill.

French, R., Jones, M., 2012. Design rainfall temporal patterns in Australian Rainfall and Runoff: Durations exceeding one hour *. Aust. J. Water Resour. 16, 21-28. doi:10.7158/W11-858.2012.16.1

Geoscience Australia, 2015. Digital Elevation Model (DEM) of Australia derived from LiDAR 5 Metre Grid. doi:10.4225/25/5652419862E23

Hammond, M., Chen, A.S., Djordjevic, S., Butler, D., Mark, O., 2015. Urban flood impact assessment: A state-of-the-art review. Urban Water J. 12, 14-29. doi:10.1080/1573062X.2013.857421

Handmer, J., Read, C., Percovich, O., Reed, C., Percovich, O., 2003. Disaster Loss Assessment Guidelines, Assessment. Dickson, Australia.

Merz, B., Kreibich, H., Schwarze, R., Thieken, A., 2010. Review article "assessment of economic flood damage.” Nat. Hazards Earth Syst. Sci. 10, 1697-1724. doi:10.5194/nhess-10-1697-2010

Middelmann-Fernandes, M.H., 2010. Flood damage estimation beyond stage-damage functions: an Australian example. J. Flood Risk Manag. 3, 88-96. doi:10.1111/j.1753-318X.2009.01058.x

Moglia, M., Tjandraatmadja, G., Delbridge, N., Gulizia, E., Sharma, A., Butler, R., Gan, K., Pollard, C., 2015. Survey of savings and conditions of rainwater tanks, Project 10TR4-001. Melbourne, Australia.

Müller, P., Wonka, P., Haegler, S., Ulmer, A., Van Gool, L., 2006. Procedural modeling of buildings. ACM Trans. Graph. 25, 614. doi:10.1145/1141911.1141931

National Water Commission, 2008. Rainwater Tank Design and Installation Handbook.

Office of Environment and Heritage, 2007. Residential Flood Damage and supporting calculation spreadsheet. Sydney, Australia.

Pebesma, E.J., 2004. Multivariable geostatistics in S: the gstat package. Comput. Geosci. 30, 683-691. doi:10.1016/j.cageo.2004.03.012

Rawlinsons, 2011. Australian Construction Handbook, 29th ed. Rawlinsons Publishing, Melbourne, Australia.

Reserve Bank of Australia, 2016. Inflation Calculator [WWW Document]. URL http://www.rba.gov.au/calculator/annualDecimal.html (accessed 5.31.16).

Smith, D.I., Greenaway, M.A., 1994. Tropical Storm Surge, Damage Assessment and Emergency Planning, Resource and Environmental Studies. Canberra, Australia. 
South East Water, 2016. South East Water - Prices and Charges [WWW Document]. URL http://southeastwater.com.au/Residential/Pages/WaterPricesCharges.aspx (accessed 6.3.16).

Stapledon, N., 2012. Trends and cycles in sydney and melbourne house prices from 1880 to 2011. Aust. Econ. Hist. Rev. 52, 293-317. doi:10.1111/j.14678446.2012.00359.x

Stevens, D., Dragicevic, S., Rothley, K., 2007. iCity: A GIS-CA modelling tool for urban planning and decision making. Environ. Model. Softw. 22, 761-773. doi:10.1016/j.envsoft.2006.02.004

Sturgess, R., 2000. Rapid Appraisal Method (RAM) for Floodplain Management. Melbourne, Australia.

Tam, V.W.Y., Tam, L., Zeng, S.X., 2010. Cost effectiveness and tradeoff on the use of rainwater tank: An empirical study in Australian residential decision-making. Resour. Conserv. Recycl. 54, 178-186. doi:10.1016/j.resconrec.2009.07.014

The State of Victoria - Department of Economic Development Jobs Transport and Resources, 2016. Victorian Soil Type Mapping [WWW Document]. URL https://www.data.vic.gov.au/data/dataset/victorian-soil-type-mapping (accessed 2.26.16).

Urich, C., Rauch, W., 2014. Exploring critical pathways for urban water management to identify robust strategies under deep uncertainties. Water Res. 66C, 374-389. doi:10.1016/j.watres.2014.08.020

Vanegas, C. a., Kelly, T., Weber, B., Halatsch, J., Aliaga, D.G., Müller, P., 2012. Procedural Generation of Parcels in Urban Modeling. Comput. Graph. Forum 31, 681-690. doi:10.1111/j.1467-8659.2012.03047.x

Velasco, M., Cabello, À., Russo, B., 2015. Flood damage assessment in urban areas . Application to the Raval district of Barcelona using synthetic depth damage curves. Urban Water J. doi:10.1080/1573062X.2014.994005

Wong, V., 2014. An investigation into infrastructure system response to climate change adaptation strategies in the Scotchman's Creek Catchment. Monash University, Melbourne, Australia. 